\title{
Assessing the potential acceptability of a new cadre of community midwives for pregnancy and delivery related care in rural Pakistan: Findings from a qualitative study
}

Abdul Wajid

Population Council

Ali M. Mir

Population Council

Zubaida Rashid

Population Council

Abida Aziz

Follow this and additional works at: https://knowledgecommons.popcouncil.org/departments_sbsr-rh

Part of the Community-Based Research Commons, Family, Life Course, and Society Commons, International Public Health Commons, Maternal and Child Health Commons, and the Women's Health Commons

How does access to this work benefit you? Let us know!

\section{Recommended Citation}

Wajid, Abdul, Ali M. Mir, Zubaida Rashid, and Abida Aziz. 2010. "Assessing the potential acceptability of a new cadre of community midwives for pregnancy and delivery related care in rural Pakistan: Findings from a qualitative study." Islambabad: Population Council. 


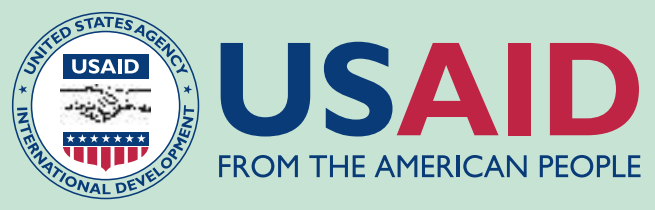

Assessing the Potential Acceptability of a New Cadre of Community Midwives for Pregnancy and Delivery Related
Care in Rural Pakistan

\section{Findings from a Qualitative Study}


Assessing the Potential Acceptability of a

New Cadre of Community Midwives for

Pregnancy and Delivery Related Care in Rural Pakistan

\title{
Findings from a Qualitative Study
}

\author{
Research Team \\ Population Council
}

Abdul Wajid

Ali Mohammad Mir

Zubaida Rashid

Independent Consultant

Abida Aziz

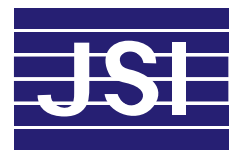




\section{(1) Population Council}

The Population Council, an international, non-profit, non-governmental organization established in 1952, seeks to improve the well-being and reproductive health of current and future generations around the world and to help achieve a humane, equitable, and sustainable balance between people and resources.

The Council analyzes population issues and trends; conducts research in the reproductive sciences; develops new contraceptives; works with public and private agencies to improve the quality and outreach of family planning and reproductive health services; helps governments design and implement effective population policies; communicates the results of research in the population field to diverse audiences; and helps strengthen professional resources in developing countries through collaborative research and programs, technical exchange, awards, and fellowships.

The Population Council reserves all rights of ownership of this document. No part of this publication may be reproduced, stored or transmitted in any form by any means-electronic, photocopying, recording or otherwise-without the permission of the Population Council.

\section{For inquiries, please contact:}

Population Council

\# 7, Street 62, F-6/3, Islamabad, Pakistan

Tel: 92518445566

Fax: 92512821401

Email: pcpak@popcouncil.org

Web: http://www.popcouncil.org

http://www.paiman.org.pk

\section{Layout and Design: Ali Ammad}

Published: March 2010

\section{Disclaimer}

"This study/report is made possible by the generous support of the American people through the United States Agency for International Development (USAID). The contents are the responsibility of JSI Research \& Training Institute, Inc and do not necessarily reflect the views of USAID or the United States Government." 


\section{Table of Contents}

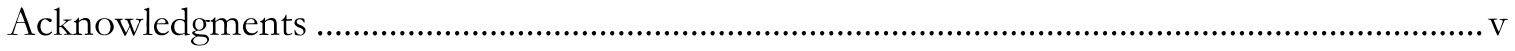

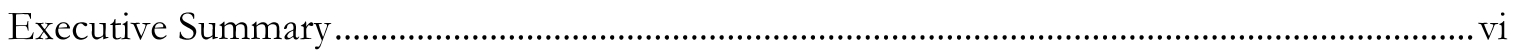

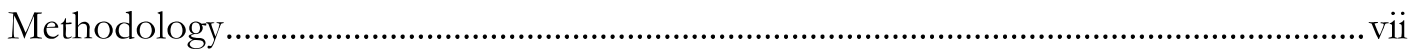

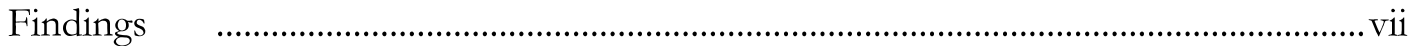

Profile of the Respondents......................................................................................... vii

Knowledge of Danger Signs ..................................................................................vii

Barriers to Accessing Health Care Services ...............................................................viii

Potential Acceptability of CMWs ............................................................................... viii

Expectations of CMWs .......................................................................................... ix

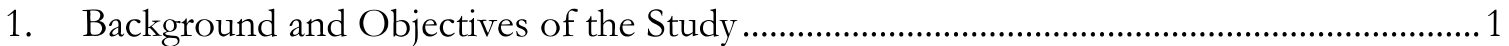

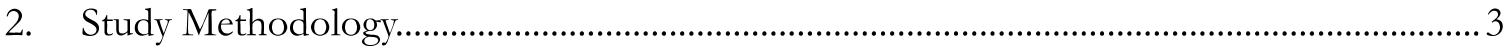

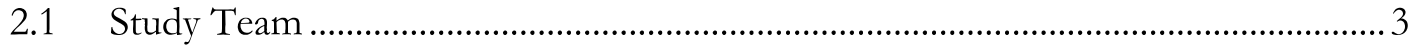

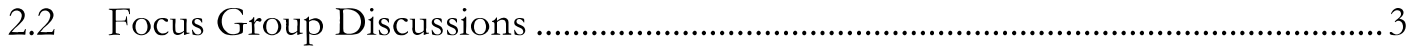

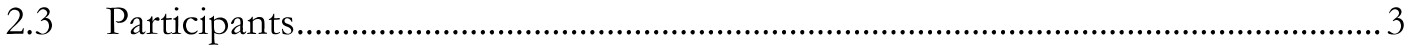

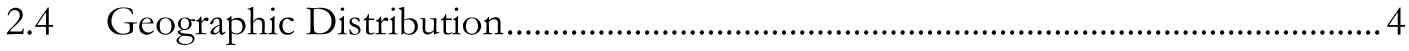

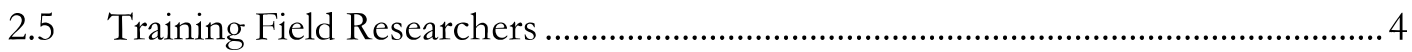

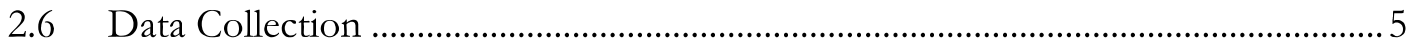

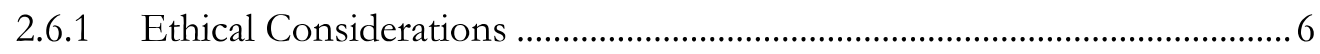

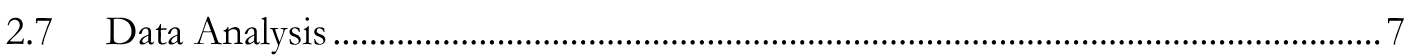

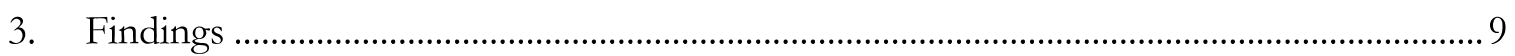

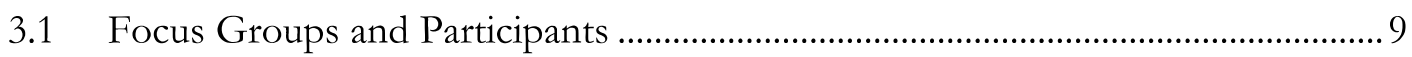

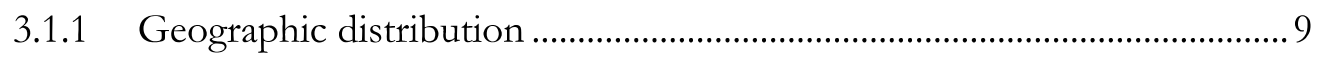

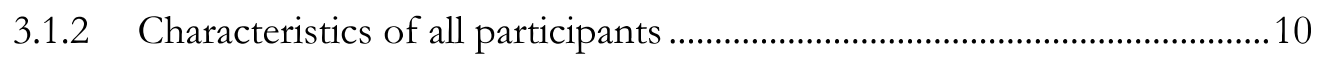

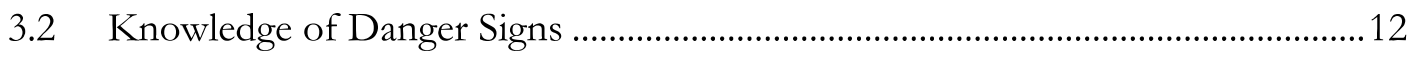

3.2.1 Danger signs during pregnancy …............................................................. 12

3.2.2 Danger signs during delivery and postpartum ..........................................13

3.2.3 Danger signs in newborns ........................................................................ 13

3.3 Access to Health Care Providers ..................................................................................... 14

3.4 Barriers to Accessing Health Care Services ............................................................ 15

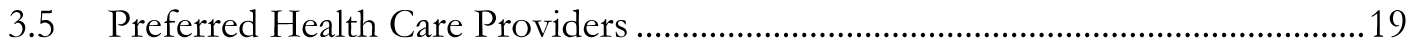

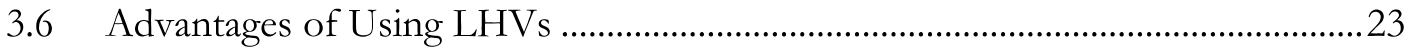

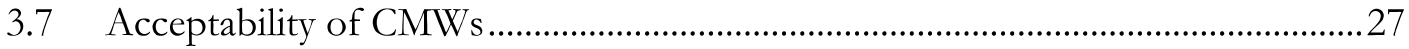

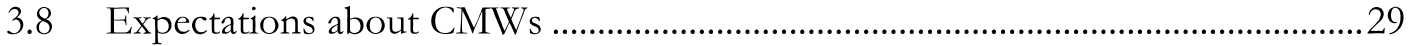




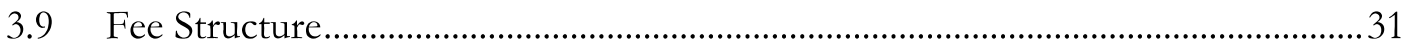

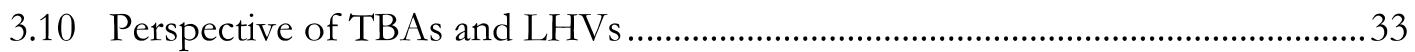

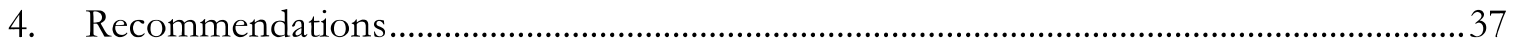

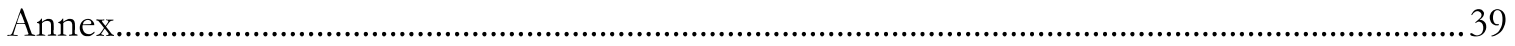

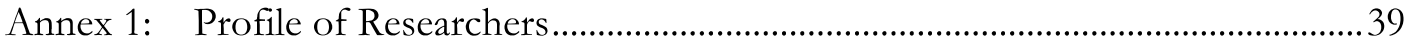

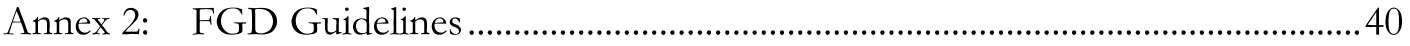

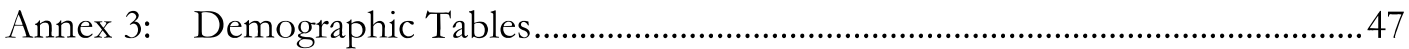




\section{Acknowledgments}

The Population Council would like to thank the Pakistan Initiative for Mothers and Newborns (PAIMAN) project for its generous funding and support for this project. PAIMAN in turn was funded by the United States Agency for International Development (USAID). In addition, we would like to appreciate the support of Dr. Nabeela Ali, Chief of Party for PAIMAN, whose support, for taking the initiative for training of community midwives and their community placement, provided the rationale for funding this study.

Dr. Zeba Sathar, as Country Director of the Population Council's Pakistan office, provided overall guidance for the successful completion of this project. She provided invaluable advice and overwhelming support throughout. We have also appreciated the support of Dr. Arshad Mahmood, head of the Operations Research Technical Working Group and Director Research, Monitoring and Evaluation, who provided technical support during the design and implementation of this study.

The report was finally reviewed by Dr. Anrudh Jain, distinguished scholar, Population Council, New York. We are so grateful to him for having so assiduously reviewed the report. We are most grateful to Ms. Pamela Ledbetter for her meticulous review of the report and her significant editorial inputs.

We acknowledge the hard work of Mr. Ali Ammad for formatting the report in a timely manner.

Finally, we want to thank the social interviewers and supervisors who undertook a very challenging assignment. The actual collection of data, of course, required their hard work and tireless efforts. We also thank the social interviewers who helped in data coding and analysis.

We also owe a debt of appreciation to all study respondents who willingly gave their time to participate in the study during long, hot summers and took the burden of our detailed inquiry. We hope that the work of this research project will repay them for their generous contribution. 


\section{Executive Summary}

Among developing countries, Pakistan has a relatively high maternal mortality rate (MMR) of 276 per 100,000 live births and neonatal mortality rate of about 54 per 1000 live births. The role of a skilled birth attendant (SBA) is very crucial in reducing high mortality. Presently only 38 percent of overall deliveries are attended to by skilled birth attendants. ${ }^{1}$

The Pakistan Initiative for Mothers and Newborns (PAIMAN) is a five-year project designed to assist the Government of Pakistan in implementing a full spectrum of interventions necessary to address mother and newborn health. The project leadership, an eight-partner consortium led by John Snow, Inc. (JSI), includes Pakistani and international organizations. ${ }^{2}$ As a partner of the consortium implementing the PAIMAN project, the Population Council oversees the evaluation component, including operations research and knowledge management of PAIMAN.

The Population Council has designed an operations research study to assess the potential acceptability of a new cadre of CMWs for pregnancy and delivery related care in rural Pakistan for the PAIMAN project. The study combines qualitative and quantitative research methods. This report presents the findings of the qualitative component carried out in the first phase of the operations research.

Specific objectives of this study were to:

$>$ Determine the need of skilled birth attendants from the perspective of target populations, including married women of reproductive age, mothers-in-law and husbands;

$>$ Identify any misconceptions regarding CMWs in the community;

$>$ Determine levels of acceptance of CMWs in the community; and

$>$ Explore barriers to the placement of CMWs in the community.

1 NIPS/USAID. 2007. Pakistan Demographic and Health Survey 2006-07. Preliminary Report. Measure DHS, Macro International Inc. Calverton, Maryland, USA.

2 The Aga Khan Foundation (AKF), Contech International Health Consultants, Johns Hopkins University Center for Communication Programs (JHUCCP), the Population Council and Save the Children USA. 


\section{Methodology}

In line with the qualitative design of the study, FGDs were used as a method for data collection. The jurisdiction of the CMWs is rural; therefore only rural communities from the four districts - Jhelum, DG Khan, Khanewal and Dadu, representing distinct cultural regions of Punjab and Sindh - were selected. CMWs selected from those areas were still under training when the data for the research were collected, therefore a standard description of CMWs was shared with the participants of FGDs. Separate FGDs were conducted with six groups of target populations: 1) literate married women with children under five; 2) illiterate married women with children under five; 3) husbands; 4) mothers-inlaw; 5) TBAs; and 6) LHVs. FGD guides were developed that contained a series of direct and indirect open-ended questions (Annex 2). Only one FGD was conducted per community. This expanded the research base to over 48 communities, 4 districts and 2 provinces.

\section{Findings}

\section{Profile of the Respondents}

A total of 375 individuals participated in the 48 FGDs. Most of the husbands were between the ages of 26 and 45 years. The majority of women were between the ages of 21 and 35years. In three districts, a majority of LHVs were 21 to 35 years of age. In Khanewal district, a little more than half of the LHVs were 36 to 55 years old. Almost all the mothers-in-law fell between the ages of 41 and 60 years. The age range of TBAs was 21 to 70 years of age. (See Annex 3.)

The participants, with the exception of LHVs, belonged to low socioeconomic segments of the population, and the education levels were correspondingly low for a majority of the participants.

\section{Knowledge of Danger Signs}

A large body of medical research suggests that MMR can be brought down if danger signs during pregnancy, delivery and postpartum are recognized and treated at an early stage. In the research study, all target groups, except husbands, ${ }^{3}$ were asked to identify the danger signs that could be associated with pregnancy, delivery and postpartum, as well as danger signs in newborns. The knowledge of the women and mothers-in-law, across all districts and groups, about the whole range of danger signs was limited; however, LHVs and TBAs were more aware.

3 During pretest of the FGD guide it was observed that married men were reluctant to discuss pregnancy or delivery related complications in a group, therefore questions related to those topics were taken out of the FGD guide for husbands. 


\section{Barriers to Accessing Health Care Services}

Multiple barriers to accessing static modern reproductive health care facilities were identified, including: 1) high fees charged by doctors for pre/postnatal checkups and delivery; 2) lack of readily available transport facilities; 3) high cost of hiring transportation to reach a health facility; 4) noncooperative attitude of doctors who work in government hospitals; 5) non-availability of required facilities in government hospitals; and 6) the restricted mobility of women. The preferred health care providers were doctors followed by LHVs and TBAs. The long list of physical barriers points to an existing gap that can be filled with trained community-based health care professionals, such as CMWs.

\section{Potential Acceptability of CMWs}

There was consensus across the districts and groups that there was a need in their communities for a trained health care professional, such as a CMW. Across the districts and groups (except for LHVs) the majority of the participants agreed that CMWs would be easily and unanimously acceptable to the communities.

A significant number of participants, mostly professional competitors of CMWs -- LHVs and TBAs - noted that CMWs acceptance would primarily depend on their performance. Other critical factors regarding potential acceptability of CMWs that were identified included conformity to local norms and friendly and respectful behavior toward clients. A significant number of LHVs and a few TBAs highlighted the likely challenges that a CMW could face in establishing a medical practice in her community. These challenges related to developing effective working relations with TBAs and LHVS, building reliable referral networks, establishing fee structures compatible with TBAs and LHVs, and fulfilling the very high expectations that community members have from all formally trained health care providers regardless of the kind of medical degree they might have.

Both groups of health care providers, TBAs and LHVs, expressed conditional willingness to work with the CMWs but proposed different working strategies. TBAs proposed: 1) referral of all delivery cases to CMWs; 2) calling on CMWs for difficult/complicated deliveries; 3) assisting a CMW during delivery; and 4) providing other services (e.g., massage, cleaning and washing) for delivery cases conducted by CMWs. In return, TBAs expected 50 percent share in delivery cases where they assisted a CMW by providing supplementary services during and after delivery and about 30-40 percent share if they refer cases to a CMW. LHVs proposed a different mechanism of cooperation. LHVs from D.G. Khan and Dadu suggested a division of territory: LHVs work till 2 p.m. or in defined clinic timings and in the areas closer to their residence or clinic. These LHVs thought a CMW could conduct deliveries after LHV run clinic timings because a CMW would be managing a home-based clinic. LHVs from Jhelum and Khanewal recommended two ways of collaboration: 1) a CMW could refer all delivery cases to an LHV and take an agreed percentage of the delivery fee charged by the LHV and 2) a CMW could carry out the normal delivery cases herself and refer cases with complications to an LHV. In the second case, LHVs were willing to give a 25 to 50 percent share of the fee to the CMW.

viii 


\section{Expectations of CMWs}

A wide range of expectations of CMWs was expressed that broadly related to five areas. The first four relate to the CMW herself and the last to facilities: 1) availability/accessibility, 2) knowledge/skills, 3) attitudes/behavior, 4) fee structure, and 5) availability of facilities.

The most often stated quality was accessibility of a CMW around-the-clock and timely assistance in emergencies. Women (literate and illiterate) placed more emphasis on easy accessibility of a CMW. Aspects of accessibility mentioned included: service around-the-clock and at home, frequent trips to houses of expecting mothers, accessibility by mobile phone, and availability of a car so that CMWs could reach patients on time. Regarding skills and knowledge, the most emphasized facets were that a CMW should be literate, able to handle complicated cases, prescribe the correct medicines, administer IV drips and injections, perform ultrasound, check blood pressure and sugar, and, most importantly, do an episiotomy ${ }^{4}$ (chotta operation). A majority of participants thought that CMWs should have a friendly and cooperative attitude. It is interesting that expectations about attitude were not mentioned by TBAs and LHVs at all.

The range of facilities that CMWs are expected to offer was very similar to what a medical doctor would provide, including ultrasound facility; blood pressure measurement; blood glucose level checkup; and injections, drips and all kinds of medicines. Expectations regarding fees CMWs should be charging were expressed at two levels: fees for checkups (both pre- and post-delivery) and fees for delivery. Across all districts, less than one-fifth of the participants, primarily TBAs, MILs, illiterate women and husbands, suggested that CMWs should not charge a fee for routine checkups during pregnancy and the post-natal period. Across the groups, women, especially literate women, were more willing to pay the CMW a fee for checkups during pregnancy. A little less than half of the participants who were willing to pay for checkups, considered amounts ranging from Rs. 20 to 50 appropriate, which is very much in line with the reported fee paid to an LHV for prenatal checkups.

A majority of participants were willing to pay a CMW for assisting in delivery. The range of the fee recommended varied greatly, from Rs. 100 to 1,000. Across the districts, an amount of Rs. 300 to 500 was considered a reasonable amount for the delivery fee. The most important aspect of the fee issue was that the participants, in general, expected a sliding scale fee structure that would meet the exceptions of both the poor and the rich, which is in line with the current practices of LHVs and TBAs.

4 An episiotomy is a surgical incision through the perineum made to enlarge the vagina and assist childbirth. The incision can be midline or at an angle from the posterior end of the vulva, is performed under local anesthetic and is sutured closed after delivery. It is one of the most common medical procedures performed on women. 


\section{Background and Objectives of the Study}

More than half a million maternal deaths and four million neonatal deaths occur during a year around the world. Among these, more than 98 percent of maternal deaths and 99 percent of neonatal deaths occur in developing countries. Among the developing countries, Pakistan has a relatively high maternal mortality rate (MMR) of 276 per 100,000 live births and a neonatal mortality rate of about 54 per 1000 live births. The child mortality rate is 94 per 1000 live births. Maternal and neonatal deaths are mainly due to the delays in recognition of complications as they arise and in seeking timely and adequate medical care. The role of a skilled birth attendant (SBA) is very crucial in reducing this high level of mortality. Presently, skilled birth attendants assist 38 percent of overall deliveries and untrained traditional birth attendants (TBAs), called dais, assist in almost 62 percent of all deliveries in Pakistan, the proportion is even higher in the rural areas, where home deliveries are a norm. ${ }^{5}$

To achieve the goals related to reducing maternal and child mortality rates set in international and national commitments, the Government of Pakistan has revised its Maternal, Neonatal and Child Health $(\mathrm{MNCH})$ Program. As mentioned before, a critical factor influencing high maternal mortality is that unskilled birth attendants assist most of the births in Pakistan; therefore, under the MNCH Program a cadre of community-based skilled birth attendants, called community midwives (CMWs) will be given training. These CMWs will be trained to conduct home-based deliveries, which will significantly increase the proportion of births assisted by skilled birth attendants in the country. This action will help achieve the target set under the United Nation's Millennium Development Goals (MDG) regarding an increase in the number of deliveries assisted by skilled birth attendants, and it will impact MMR through early detection and timely referral of obstetric and newborn complications.

The Pakistan Initiative for Mothers and Newborns (PAIMAN) is a five-year project designed to assist the Government of Pakistan in implementing the full spectrum of interventions necessary to address mother and newborn health. The PAIMAN team has been working closely with the Ministry of Health, Government of Pakistan, in formulating the vision and strategies for the project. The project leadership, an eight-partner consortium led by John Snow, Inc., includes Pakistani and international organizations: the Aga Khan Foundation (AKF), Contech International Health Consultants, Johns Hopkins University Center for Communication Programs (JHUCCP), the Population Council and Save the Children USA.

As a partner of the consortium implementing the PAIMAN project, the Population Council oversees the evaluation component, including operations research and knowledge management of PAIMAN. The Population Council's role is to ensure the success of PAIMAN and that the appropriate lessons

5 NIPS/USAID. 2007. Pakistan Demographic and Health Survey 2006-07. Preliminary Report. Measure DHS, Macro International Inc., Calverton, Maryland, USA. 
are learned. The Population Council has designed an operations research study: Assessing the Potential Acceptability of a New Cadre of CMWs for Pregnancy and Delivery Related Care in Rural Pakistan. The purpose of this study is to understand the potential acceptability of CMWs in their respective communities and to assess the impact of their knowledge and skills regarding $\mathrm{MNH}$. The findings of this operations research study will provide the necessary evidence on which future decisions regarding the placement and practices of community midwives will be based. The proposed study combines qualitative and quantitative research methods.

This report presents the findings of the qualitative component of the study carried out in the first phase of the operations research.

Specific objectives of the study were to:

$>$ Determine the need for skilled birth attendants from the perspective of target populations that included married women of reproductive age, mothers-in-law and husbands;

$>$ Identify any misconceptions regarding CMWs in the community;

Determine levels of acceptance of CMWs in the community; and

$>$ Explore barriers to the placement of CMWs in the community.

To meet the study objectives, 48 focus group discussions (FGDs) were held in 4 selected districts. 


\section{Study Methodology}

\subsection{Study Team}

A male and female public health physician and a research consultant (an anthropologist) led this study. In addition to the core team, 21 field researchers ( 7 men and 14 women) were hired to collect data. Four teams of field researchers were formed, one for each district. Each team comprised of a logistic coordinator, two moderators (male and female) and two note takers (male and female). Several considerations were taken into account with respect to the selection of researchers, such as prior work experience, fluency in the local languages and satisfactory performance during the training. (See Annex 1.)

\subsection{Focus Group Discussions}

In line with the qualitative design of the study, focus group discussions were used for data collection. FGDs were considered suitable for this research study because this technique produces data and insight that are highly accessible due to interactions found in a group setting - listening to the experiences and opinions of others, which stimulates ideas and experiences in participants. In a group discussion, people tend to center their opinions on the most common ones, or social norms; hence, focus groups have a high apparent validity. In order to ensure validation, information was obtained on selected topics from several different categories of informants who were likely to discuss the topics from different perspectives.

Separate FGDs were conducted with each group because literature suggests that homogenous age and sexual composition of a group facilitate open discussion. An attempt was made to cover low income but diverse populations; for this purpose, selection criteria were used to assess the socioeconomic status of the participants.

In order to understand the knowledge and attitudes of each group, three separate guidelines were designed for the target groups. These FGD guides contained a series of direct and indirect openended questions. (See Annex 2.)

\subsection{Participants}

In light of the objectives of the study, the following six population groups were identified as target groups:

$>$ Married women with children under five (literate group)

Married women with children under five (illiterate group) 
$>$ Husbands

Mothers-in-law

$>$ TBAs

LHVs

Selection criteria were determined for each of these groups. Keeping in view the reproductive period for women and the average age of marriage in Pakistan, the age range defined for women was 15 to 49 years. The age range for men was between 20 to 60 years. Married women and men having at least one child of five years or below were selected for the study.

Mothers-in-law were selected below the age of 60 years because of their relative mental alertness and likely active involvement in the reproductive health of the family. It was agreed among the team that mothers-in-law above the age of 60 would not be made part of the study due to health problems (impaired hearing, etc.) and social inactivity found at older ages. Another condition included in the selection criteria was that only mothers-in-law who had one grandchild less than 5 years of age would be selected for the study.

TBAs selected to take part in the research study were to be less than 65 years of age. In order to ensure inclusion of currently active LHVs and TBAs in the study, one criterion for the selection of LHVs and TBAs was that they should have delivered at least four children in the last two months.

\subsection{Geographic Distribution}

The jurisdiction of the CMWs is rural; therefore, only rural communities from the four districts Jhelum, D.G. Khan, Khanewal and Dadu, representing distinct cultural regions of Punjab and Sindh -- were selected. In order to tap into a larger knowledge base and to obtain a more diverse representation, only one FGD was conducted per community. This expanded the research base to over 48 communities in 4 districts in 2 provinces.

\subsection{Training Field Researchers}

A six-day training session was held in Islamabad from March 31 to April 5, 2009, for the field researchers. Two major objectives of this training were: 1) to familiarize the researchers with the scope of the research study, FGD guides and selection criteria and 2) to build skills in facilitating and documenting FGDs. The main features of the training are summarized below.

The first session consisted of sharing the significance of the study with the trainees. Then the participants learned about issues surrounding mother and child mortality and the CMW initiative launched by the Government of Pakistan. The trainees were then introduced to FGD guides. To 
ensure understanding of the FGD guides, an initial exercise of role-playing was conducted where the trainees were divided into groups imitating the actual target groups. To assist in clearing away any ambiguities, detailed discussions among the trainers and the trainees followed. To build their understanding, the participants were also asked to translate the FGD guides into their mother tongues (Punjabi, Siraiki and Sindhi).

During the first two days the trainees were divided into three groups for skill building; within each group each trainee practiced both facilitation and note taking. In the following four days, trainees conducted FGDs with selected segments of the target population in the outskirts of Islamabad and Rawalpindi, while the core team members observed them. Keeping in mind cultural sensitivities, female members of the core team observed FGDs with women, TBAs and LHVs, while male members observed FGDs with husbands. According to their planned roles, the trainees were given many opportunities to practice facilitation and note taking.

It is noteworthy that in addition to the capacity building of the trainees, the training sessions in the field also allowed for additional pre-testing and fine-tuning of the FGD guides.

\subsection{Data Collection}

Data were collected through 48 FGDs conducted in the jurisdiction of the CMWs, which are essentially rural communities, in four districts in Jhelum, D.G. Khan, Khanewal and Dadu. A member of the core team, in collaboration with the $\mathrm{MNCH}$ Program compiled a list of the CMWs catchment areas in the four target districts and from those lists communities were selected according to the guidelines provided to the research teams. The area where the research was to be conducted was decided after consultations between core team members and logistics supervisors. Several factors were taken into account for the selection of communities, including the security and safety situation, accessibility, distance and travelling time, wheat-harvesting season, and that the area represented the mainstream population. At the same time, to ensure adequate representation, several steps were taken: one FGD per community was conducted expanding the geographical spread of data collection, equal numbers of FGDs were conducted in all four districts, and the overall profile of communities selected was matched roughly in terms of distance from the road and religious and social population dynamics of the population.

The participants were selected from low socioeconomic class and pre-designed selection criteria were used to select participants. It was ensured that the criteria were adhered to in the field and that the field researchers sent back all of the screening forms filled out in the field for review by the core team.

The quality of FGDs was enhanced by allowing adequate time to complete all of the steps of an FGD. The teams were allowed 3 days per FGD. The first day was to be utilized in organizing the group, the second to conduct the FGD and the third to make the transcription. The logistics officer and facilitator made contact with the community directly. This was to avoid the involvement of any 
influential person in the selection of the respondents, as this might have compromised the neutrality of the data. However, the teams faced questions from influential people in the community and were always able to satisfy their curiosity regarding the purpose and methods of the research.

Using the criteria form, team members screened potential respondents and, after obtaining their consent, invited them to participate in the discussion the next day. For each FGD the teams always selected one or two persons above the required number of participants as experience showed that one or two selected respondents would usually not be available for the FGD planned for the next day.

An appropriate venue was identified for conducting a FGD in a community prior to the identification of respondents. The places selected were neutral (e.g., schools and health houses) far from noise, pleasant enough to allow sitting for an hour at least, as well as easily accessible. Light refreshments were also arranged for the participants, which were usually served after the completion of the FGD.

Adequate documentation of FGDs was ensured. All of the FGDs were tape-recorded and a trained note taker documented the discussion. Depending on the availability and interest of the participants, FGDs took 70 to 90 minutes to finish. All of the topics identified in the FGD guide were explored in-depth during the discussion.

One and a half days were allocated to prepare the transcription of each FGD. A full report of the discussion, using the participants' own words, was prepared, which reflected the discussion as comprehensively as possible. The note takers listened to the tape-recorded conversations and filled in the gaps in their notes. Then the completed transcriptions were reviewed by the facilitator to ensure that of the all the points discussed were fully captured.

\subsubsection{Ethical Considerations}

In this research study, the standards of appropriate professional behavior were maintained without any compromises due to obligations to funders/employers, subjects or society. In this regard, the following ethical points were taken into consideration:

$>$ Methods, procedures and findings of the research study were open to collegial review;

$>$ Concerns for the safety and security of colleagues when conducting field research were addressed;

$>$ Informed consent of the participants was sought;

$>$ The confidentiality of information supplied by research subjects and the anonymity of respondents was completely respected;

The research staff and the participants were informed fully about the purpose, methods and 
intended possible uses of the research, what their participation in the research entailed, and what risks, if any, were involved.

It was ensured that participation in the research was voluntary and free from any coercion.

\subsection{Data Analysis}

One member of the core team, the research consultant, had primary responsibility for conducting the analysis of FGDs at the Population Council office in Islamabad. A group of field researchers assisted her in data compilation and analysis; their input was especially valuable, as all of them had been involved in this research study as focus group facilitators and note takers.

As stated earlier, each FGD was recorded and the tapes from each focus group session were transcribed, capturing the exact words and phrases, voiced by the participants. As a first step toward data analysis, these transcripts were read and the tape recordings of the discussions were listened to multiple times. The team was well aware of the fact that more familiarity makes various themes and patterns more obvious. The patterns, key points, and major themes that emerged from the review of each FGD were identified. The words, key phrases, major quotes or sentences typifying certain patterns were recorded. The next step was to organize responses according to each research question in the topic guide. Finally, comparisons across districts and population groups were drawn and findings were substantiated with key phrases from the transcriptions. 


\section{Findings}

\subsection{Focus Groups and Participants}

The jurisdiction of the CMWs is rural; therefore, FGDs were conducted in 48 rural communities from four districts - Jhelum, D.G. Khan, Khanewal and Dadu. One FGD per community was conducted. (See Annex 3.)

\subsubsection{Geographic distribution}

\section{Geographic distribution of focus groups}

An equal number of FGDs across the categories and the districts was maintained, with a total of 48 FGDs held in the rural areas of the four districts. Table 1 lists the distribution of FGDs across districts and target groups.

Table 1: Number of focus groups, by target group and district

\begin{tabular}{l|r|r|r|r|r}
\hline Target group & Dadu & D.G. Khan & Jhelum & Khanewal & Total \\
\hline Mothers (illiterate) & 2 & 2 & 2 & 2 & $\mathbf{8}$ \\
\hline Mothers (literate) & 2 & 2 & 2 & 2 & $\mathbf{8}$ \\
\hline Husbands & 2 & 2 & 2 & 2 & $\mathbf{8}$ \\
\hline Grandmothers & 2 & 2 & 2 & 2 & $\mathbf{8}$ \\
\hline LHVs & 2 & 2 & 2 & 2 & $\mathbf{8}$ \\
\hline TBAs & 2 & 2 & 2 & 2 & $\mathbf{8}$ \\
\hline Total & $\mathbf{1 2}$ & $\mathbf{1 2}$ & $\mathbf{1 2}$ & $\mathbf{1 2}$ & $\mathbf{4 8}$ \\
\hline
\end{tabular}

\section{Geographic distribution of participants}

A total of 375 persons participated in the 48 FGDs conducted in four districts of Punjab and Sindh. Table 2 shows that there was minimal numerical variation across categories and districts. The number of participants was almost equal in three districts (D.G. Khan, Khanewal and Dadu) and was slightly lower in one district (Jhelum); this shows a nearly equal distribution of participants across the districts and provided a relatively even base for the analysis. 
Table 2: Number of focus group participants, by target group and district

\begin{tabular}{|c|c|c|c|c|c|}
\hline Target group & Dadu & D.G. Khan & Jhelum & Khanewal & Total \\
\hline Mothers (illitrate) & 16 & 20 & 13 & 18 & 67 \\
\hline Mothers (literate) & 14 & 18 & 17 & 16 & 65 \\
\hline Husbands & 20 & 15 & 14 & 13 & 62 \\
\hline Mothers-in-law & 17 & 17 & 15 & 20 & 69 \\
\hline TBAs & 15 & 14 & 13 & 18 & 60 \\
\hline LHVs & 13 & 13 & 13 & 13 & 52 \\
\hline Total & 95 & 97 & 85 & 98 & 375 \\
\hline
\end{tabular}

\subsubsection{Characteristics of all participants}

\section{Age}

The age of husbands who participated in the study ranged from 19 to 60 years; however, across the districts most of the husbands were between the ages of 26-45 years. The age range of women who participated in the FGDs was 15 to 45; however, the majority of women were between the ages of 21 to 35 years. Similarly, in the three districts, a dominant majority of LHVs were in the age group of 21-35 years. In Khanewal district, a little more than half of the LHVs were in the age group of 36-55 years. Across the board, almost all of the mothers-in-law fell between the ages of 41 to 60 years. The age range of TBAs was 21 to 65 years. In Dadu, the majority of TBAs were 46 to 60 years old, while in Jhelum and D.G. Khan about two-thirds of the TBAs were in the age group of 26 to 50 years. In Khanewal, majority of the TBAs were 20 to 45years of age. (See Annex 3.)

\section{Education}

The participants, with the exception of LHVs, belonged to low socioeconomic segments of the population and the education levels were correspondingly low for a majority of the participants. Across the three districts of Jhelum, Dadu and D.G. Khan, almost one-third of the participants were illiterate. In Khanewal, almost half of the participants were illiterate. By design, the number of literate and illiterate women was equal across all four districts. There were variations in education levels among husbands. In D.G. Khan, almost half of the husbands who participated in the study were illiterate. However, in Dadu more than half of the husbands had 5 or more years of schooling, in Khanewal almost half of the husbands had 4-9 years of schooling, and in Jhelum a majority of the husbands had more than 8 years of education. The lowest literacy levels were found amongst MILs and TBAs. Almost all MILs from Jhelum, Khanewal and Dadu were illiterate, while in D.G. Khan less than half of the MILs were illiterate. Almost all of the TBAs from Dadu and D.G. Khan, and more than half from Jhelum and Khanewal, were illiterate. (See Annex 3.) 


\section{Occupation}

The husbands who participated in the study were asked about their occupation. Women and mothers-in-law who participated in the study also noted the occupation of their husbands. Across the districts, a wide range of occupations was mentioned, including self-employment, manual labor, government service and farming. Across the districts, the three major occupations mentioned were farmer, laborer and government servant. (See Annex 3.)

\section{Children}

Husbands and women who participated in the FGDs were asked about the number of children they had. The number of children reported ranged from 1 to 13. Almost two-thirds of literate women and one-third of illiterate women had two or less children. The difference in numbers of children between literate and illiterate women was clear. A larger proportion of the participants (husbands and women) from Dadu, Khanewal and D.G. Khan had more than 3 children. While a larger number of participants from Jhelum had 3 or less children. Mothers-in-law were also asked about the number of grandchildren they had. Half the mothers-in-law had grandchildren under the age of two years. (See Annex 3.)

\section{Babies delivered by $L H V s$ and TBAs}

In all four districts, most of the LHVs and TBAs reported to have delivered less than 15 children in the last two months. Of these, more than half delivered less than five children. The differences across groups and districts in the three districts of Jhelum, Dadu and D.G. Khan regarding the number of children delivered by LHVs and TBAs were negligible. The situation was slightly different in Khanewal as all TBAs from this district reported to have delivered less than five babies in the last two months. (See Annex 3.)

\section{Experience of LHVs and TBAs}

Overall, the average years of experience of the health care providers who participated in the research was 9.5 years. In three districts, Jhelum, D.G. Khan and Dadu, the TBAs were, on average, 5 years more experienced than the LHVs. Average years of experience for LHVs were almost the same across the three districts. TBAs from D.G. Khan were most experienced with an average of 19 years, followed TBAs from Dadu with an average of 13 years, and then Jhelum where the average was 9 years. This scenario was reversed in Khanewal where the LHVs were more experienced than the TBAs. LHVs from Khanewal averaged 15.6 years of experience, while TBAs averaged 8.5 years of experience. (See Annex 3.) 


\subsection{Knowledge of Danger Signs}

\subsubsection{Danger signs during pregnancy}

A large body of medical research suggests that a pregnant woman may experience complications, such as high blood pressure, high fever, edema (swelling), severe abdominal pains, severe vomiting and vaginal spotting. In this research study, all target groups except husbands ${ }^{6}$ were asked to identify the danger signs that could be associated with pregnancy. The knowledge of the women and mothers-in-law, across all districts and groups, about the whole range of danger signs was limited. Most commonly identified danger signs were vomiting and high blood pressure, as these were mentioned by about two-thirds of all participants. Across the four districts, very few participants mentioned many critical danger signs, such as high fever, severe abdominal pain, vaginal spotting and swelling. With regard to complications during pregnancy, most of the women and mothers-in-law mentioned symptoms associated with danger signs, such as pains and aches in the body, weakness, lack of appetite, lethargy, dizziness and heartburn, rather than the danger signs themselves.

Across the districts, the health care providers, LHVs and TBAs, were more aware of the dangers during pregnancy than the women and mothers-in-law. Among the two groups, LHVs recognized a broader range of danger signs than the TBAs. The LHVs, particularly from Dadu, Khanewal and Jhelum, were comparatively more informed about danger signs. The TBAs laid greater stress on symptoms such as weakness, pains, heartburn and lethargy. Across the districts, the most commonly identified danger sign by the LHVs and TBAs was hypertension, followed by vomiting, vaginal spotting and edema. Other problems mentioned in connection with pregnancy were anemia, hepatitis, body pains, weakness and acidity. Jaundice was also mentioned by a few TBAs as a danger sign. In the Khanewal district, a few misconceptions surfaced during the discussion:

Severe vomiting can change the position of baby into a breach.... High blood pressure may cause a stillbirth. (TBA, Khanewal)

Across the groups, mothers-in-law were most vocal and offered the maximum information on this topic, followed by literate women. Across the districts, many mothers-in-laws mentioned technical and critical problems, such as anemia (the exact term used for this condition was kbun ki kami) and high/low blood pressure. It was reported that mothers-in-law often accompany their daughters-inlaw to visit health care providers. Mothers-in-law were probably more aware because of frequent contact with doctors and other health professionals, as well as due to longer years of experience.

6 During pretesting of the FGD guide it was observed that married men were reluctant to discuss pregnancy or delivery related complications in a group; therefore, questions related to those topics were taken out of the FGD guide for husbands. 


\subsubsection{Danger signs during delivery and postpartum}

According to medical research, during delivery and postpartum, high blood pressure, fits, prolonged labor, obstructed labor, postpartum hemorrhage ( $\mathrm{PPH})$, delayed delivery of the placenta and high fever are signs of danger requiring urgent hospitalization for comprehensive medical care.

Across the districts, the level of awareness among the women and mothers-in-law about the whole spectrum of danger signs was limited. Less than half of the participants mentioned at least one of these signs during the discussions. Across the broad spectrum, the most commonly recognized danger sign was excessive bleeding, followed by prolonged labor, fits due to tetanus, high fever and delayed delivery of the placenta. Related symptoms mentioned by a few participants included high blood pressure, wrong position of the baby during delivery and infection in the stitches. Across the districts, the mothers-in-law were more aware of these danger signs than the daughters-in-law.

Across the districts, LHVs and TBAs were more aware of danger signs during delivery and postpartum than the women and mothers-in-law. The danger signs most commonly recognized by LHVs and TBAs were prolonged labor, delayed delivery of the placenta, fits and postpartum hemorrhage. In Khanewal district, two commonly recognized danger signs were obstructed labor and $\mathrm{PPH}$; of these, obstructed labor was primarily identified by women, while $\mathrm{PPH}$ was mentioned primarily by LHVs, TBAs and literate women. The TBAs, particularly from Dadu, seemed more aware of danger signs during delivery than the LHVs. Weakness was an additional postpartum problem mentioned across the districts by a significant number of LHVs and TBAs.

Jaundice proved to be a unique case, as it was mentioned in all four districts and by all of the groups as a danger sign during pregnancy, during the postpartum stage and in the newborn. This is probably due to the high prevalence of the disease in Pakistan.

\subsubsection{Danger signs in newborns}

According to medical research, major danger signs in neonates include: inability to suckle, difficulty in breathing (birth asphyxia), high fever, baby turning blue, diarrhea and infection of the umbilical cord.

Among all of the groups, LHVs and TBAs were more informed about the danger signs than the women and mothers-in-law; however, even among these two groups, the recognition of danger signs in newborns remained low. Across the districts, about half of the LHVs and TBAs were able to recognize at least one danger sign accurately. The most commonly identified danger sign in newborns was difficulty in breathing, followed by pneumonia, tetanus, diarrhea, blue baby, infection in the umbilical cord, and difficulty in suckling. Fever, which is a sign of infection, was not mentioned by anyone.

Across the districts, recognition of danger signs in newborns was low among mothers-in-law and women: less than one-third of them recognized at least one danger sign. Interestingly, across the districts, jaundice was the most commonly mentioned danger sign by women and mothers-in-law. A 
significant number of women (both literate and illiterate) and mothers-in-law from D.G. Khan mentioned birth asphyxia. In the Khanewal district, the most commonly identified danger sign in newborns was difficulty in breathing (birth asphyxia), which was mentioned primarily by LHVs and literate women. Birth asphyxia was referred to as oxygen ki kami. Across the board, only a couple of participants mentioned each of the following danger signs: diarrhea, vomiting, tetanus, high fever, blue baby, infection or bleeding in umbilical cord, anemia, and when a baby doesn't cry at birth. Again, the mothers-in-law seemed as informed as mothers of young children did and the level of awareness was almost similar across the districts.

In summary, the overall recognition of danger signs during pregnancy, delivery, postpartum and for the newborn was low among women and mothers-in-law as well as among health care providers (TBAs and LHVs). Mothers-in-law, especially from Dadu and D.G. Khan, were relatively more aware of the danger signs related to pregnancy and delivery than the women were. Among health care providers, the differences in the level of awareness were more pronounced across the districts. The LHVs and TBAs from Jhelum were more aware of danger signs compared to the findings from the other three districts. This could probably be attributed to longer PAIMAN presence in the district and a better overall level of social development indicators in the district.

\subsection{Access to Health Care Providers}

Availability of at least one health care provider in the near vicinity was reported by all of the groups; however, the type of these varied widely - ranging from TBA, LHW, LHV, BHU, RHC, Family Welfare Centre, government/private hospitals, and private doctors. Across the districts, and particularly in Dadu, TBAs were the most commonly available and easily accessible health care providers, followed by LHWs and LHVs. Compared with the other two districts, the presence of LHVs was more widely reported in Dadu and Khanewal. Across the groups, husbands were least aware of the presence of LHWs and LHVs in their communities. A significant number of participants, almost half of them from Dadu, cited availability of doctors/ hospitals (BHUs/RHCs).

In Khanewal district, a few husbands, literate women and mothers-in-law specifically brought up the issue of the non-availability of a female doctor in the government hospitals in their near vicinity:

There is a government hospital nearby but the post of lady doctor has been lying vacant for a long time, so this facility is of no use to us, women do not consult male doctors regarding pregnancy and delivery related problems. (Mother-in-law, Khanewal)

It was also reported that PAIMAN staff members have been conducting health education sessions and have assisted in a few deliveries as well. 


\subsection{Barriers to Accessing Health Care Services}

The following barriers to accessing static modern reproductive health care facilities were identified:

1. High fees charged by the doctors for pre/postnatal checkup and delivery

2. Lack of readily available transport facilities

3. High cost of hiring transportation to reach a health facility

4. Non-cooperative attitude of doctors in government hospital

5. Non-availability of required facilities in the government hospitals

6. The restricted mobility of women

In the following section, these barriers are discussed in detail.

The health care provider's fee was the most cited barrier in Dadu and D.G. Khan. Across the board, it was reported that only complicated cases were taken to a hospital. Across the districts, the cost reported for a complicated delivery ranged from Rs. 6,000 to 35,000, even when the treatment was provided in a government hospital.

Doctors charge Rs. 20,000 for a delivery case, we have to sell our animals to pay, otherwise doctors would not touch a woman even if she dies on the clinic's doorstep. (Husband, D.G. Khan)

Government hospitals don't charge us any fee but they give us medicine and surgical prescriptions and ask us to buy them, and it totals to around the same amount. When we go to get a checkup, it costs us around a thousand rupees. A woman from our village fell ill, and we took her to Larkana for delivery and there it cost us Rs. 35,000. The man sold bis cattle to pay for his wife's treatment and his child didn't survive either. (Mother-in-Law, Dadu)

In Khanewal, the cost reported for a normal delivery at a health facility (government or private) ranged from Rs. 3,000 to 6,000, and costs reported for complicated delivery cases ranged from Rs. 6,000 to 20,000 .

In a private hospital they ask for Rs. 20,000 for a delivery case and in government hospitals patients have to provide medicines and staff asks for 'mubarki' money, one has to pay at least Rs. 3,000 to 4,000 in this category. Still in a government hospital the cost of delivery is one-fourth of the cost incurred in a private hospital. (Husband, Khanewal)

The second major barrier reported across the districts and mentioned by a relatively larger number of participants from D.G. Khan was the timely availability of transportation to reach a health facility. Across the groups, husbands and women (literate and illiterate) emphasized this barrier more than the other groups. A significant number of participants, mostly from D.G. Khan and Dadu, 
mentioned the issue of distances that need to be covered in order to reach the health facilities.

First of all it is very difficult to find transport in time, and when it is found, the driver charges whatever he likes, Rs. 4,000 to 8,000. (Husband, D.G. Khan)

Sometimes the transportation is not available to take the woman in labor to a bealth facility, then the rich and influential persons of the village such as Sardars are requested to lend their personal car; they sometimes oblige and other times they refuse. (Husband, Khanewal)

The third most cited barrier, reported only by the women from all three districts, was difficulty in seeking permission, both for the purpose of checkups during pregnancy as well as for delivery. There was a consensus across the districts and groups that permission was indeed required for married women to visit a health facility for pre/postnatal checkups as well as for delivery. Across the board, husbands and mothers-in-law were mentioned as the two main family members whose permission was required prior to visiting a health facility. Although both husband and mother-in-law were mentioned in all four districts, the level of emphasis varied across districts. In D.G. Khan and Dadu, mothers-in-law played a more dominant role in decision making regarding visits to a health facility, while in Jhelum the practice of seeking permission from the husband was more commonly reported. In the Khanewal district, the level of emphasis varied across the groups and two slightly different group-specific patterns emerged: husbands identified mothers-in-law as the family member whose permission was needed, while all other groups mentioned both husband and mother-in-law.

If you don't ask, the mother-in-law for permission, she gets upset because she wasn't asked. A woman can't come without mother-in-law's permission. (LHV, D.G. Khan)

Mothers-in-law never give permission to take the women to hospital, therefore we do not even try to seek permission from them and talk directly to busbands who understand the situation more quickly and are ready to take the women to hospital in time. (TBA, Jhelum)

Permission should be taken from in-laws and husband, but mainly mother-in-law's permission is needed, and if she does not agree and refuses to give money, this can cause problems. (Literate woman, D.G. Khan)

When parents are alive then their permission is essential, also mother often accompanies the woman to hospital. (Husband, Khanewal)

Across the districts and groups, and particularly from D.G. Khan, it was reported that TBAs often played a key role in a family's decision regarding the place of delivery - whether it should be facility based or home based. When a TBA recommended at some stage, that a woman be taken to a hospital the family members usually took her advice. 
The elder woman in the family and TBA tell us if a there is a problem with the delivery of a child at home, and if the TBA suggests, we arrange for money, transportation and rush the woman to the hospital. (Husband, D.G. Khan)

The research findings indicated that women required permission of their husband and/or mother-inlaw to visit a health facility. The question of how easy or difficult it was to obtain the permission was discussed in depth. Across the districts, it was reported that permission for routine checkups during pregnancy was more difficult to get than the permission to go to a health facility for a delivery case with complications; however, the level of ease varied across districts and groups. In the Khanewal district, a significant number of women, TBAs and LHVs reported that getting permission for routine prenatal checkups was not always easy, particularly where the distances to get to a doctor were greater.

Mothers-in-law do not encourage their daughters-in-law to see doctors for pre/postnatal checkups and often stop them, and young daughters-in-law do not dare get out of the house without her mother-in-law's permission, and husbands also often tell their wives to get permission from their mother-in-law. (LHV, Khanewal)

All groups (except LHVs) from Jhelum and D.G. Khan stated that for difficult delivery cases permission to take the woman to hospital was granted readily. In Dadu, a significant number of illiterate women, TBAs and LHVs reported that permission was not easily granted even for complicated delivery cases. It is noteworthy that none of the husbands and, with a few exceptions, none of the MILs acknowledged that pregnant women faced any difficulties in getting permission to visit health clinics for checkups or delivery. It is interesting that across the district, on the issue of permission, a significant number of the LHVs strongly stated that women were not easily granted permission to have checkups during pregnancy and for facility-based delivery. Discussing the reasons for not giving permission, many LHVs and some women hinted that many times the issue of permission came up due to monetary constraints. Many LHVs believed it was the strength of tradition: mothers-in-law preferred that their daughters-in-law should follow their own tradition of delivering babies at home.

The circumstances are such that permission has to be granted. If a wife bas to be taken to a hospital, everybody grants permission because the situation is such that she could die. (Husband, Jhelum)

If husband and mother-in-law are not considerate enough they keep delaying the decision to take a woman to hospital, even when the case is complicated. (TBA, Dadu)

In some houses, the mother-in-law does not allow the daughter-in-law to go to the bospital because they believe in traditional methods and say that they themselves were delivered at home. (LHV, Dadu) 
Those who cannot afford it, don't give permission, they say, 'die from the pain'. Nobody even loans money to a poor person. (Literate woman, D.G. Khan)

In order to explore male-specific cultural barriers, husbands were asked an explicit question about whether they feel embarrassed while accompanying their pregnant wives to the health facilities. Across the districts, most of the husbands negated the proposition:

At this crucial time when even death can occur, people do grant permission and there is nothing to be ashamed about. (Husband, Jhelum)

These are the times of high awareness, radio and TV has changed everything, men now understand that if they do not take their wives, who are suffering from a problem related to pregnancy or delivery, they could die so feeling embarrassed is out of the question. (Husband, Khanewal)

Only a few husbands, mostly from D.G. Khan and Dadu, accepted that they did, in fact, feel embarrassed while accompanying their wives to hospitals for pre/postnatal checkups and delivery:

Men from the village felt ashamed taking women to the hospital and prefer that delivery happens in the village. (Husband, D.G. Khan)

In the village environment people do feel ashamed going to the hospital but when the woman is near death, they have no choice. (Husband, Dadu)

The fourth barrier reported across the districts primarily by women (both literate and illiterate) and husbands was women's restricted mobility. When women did get permission for checkups during pregnancy they could not go to a health care provider alone; most often their husbands, mothers-inlaw or both accompanied them. In case of delivery, additional family members and sometimes TBAs also accompanied women to health facilities. Reportedly, due to this dependence on others, women often did not make it to a health facility, especially for pre- and postnatal checkups.

The daughter-in-law tells her problem to her mother-in-law and she takes her to a doctor or LHV. (TBA, Khanewal)

Only old women go to a bealth facility alone, young women are always accompanied by an older family member or busband. (Literate woman, Khanewal)

The fifth barrier reported across the districts by a significant number of women only, was the noncaring attitude of the doctors and lack of empathy. It was reported that despite charging high fees doctors did not properly attend to their patients. The following statements sum up these issues that were raised very bluntly: 
They [doctors] are irritable and often scold us. (Illiterate woman, Jhelum)

In government hospitals, doctors and administrative staff do not attend to the patient on time and often these delays have caused the deaths of many women in labor. (Mother-in-law, Khanewal)

In a government hospital doctors do not attend to the poor patients unless they bave come with a reference from a politician -- due to this fear people take women to private hospitals. (Husband, Khanewal)

The sixth barrier mentioned by women, husbands and mothers-in-law from all of the districts, though more widely from Dadu, Khanewal, and D.G. Khan, was the non-availability of facilities in the tehsil and sometimes district-level hospitals. It was reported that after all the trouble of reaching a health facility it often happened that all of the health care amenities, such as operation theatre, female gynecologist and ultrasound machine in working condition, were not available and women patients were referred from one health facility to another.

For delivery we started with a TBA, she could not handle it. Even when we did not have money, we took the woman to Khairpur; doctors at the Khairpur hospital asked us to take her to Dadu, in Dadu there was no female gynecologist and doctors told us to take her to Larkana, so we just kept spending money. (Mother-in-law, Dadu)

In government hospitals often medicines are not available, and sometimes lady doctors are not there to attend to women and junior LHVs or TBAs bave to conduct the deliveries. (Literate woman, Khanewal)

In summary, a number of physical and social barriers were identified in accessing health facilities for reproductive health services, particularly those related to pre- and post-natal checkups and facilitybased deliveries. This situation points to an existing gap that can be filled with trained community based health care professionals such as CMWs.

\subsection{Preferred Health Care Providers}

Access to health care services is one thing and getting satisfaction from them is another. The participants were asked about who could provide a woman with the most satisfactory reproductive health care services. Across the groups, less than half of the participants from Dadu and D.G. Khan and slightly more than half of the participants from Jhelum considered a doctor, particularly a female doctor, to be the most satisfactory health care provider. In Khanewal, a majority of women, husbands, mothers-in-law and TBAs considered a female doctor to be the preferred provider. It should be noted that this category included doctors in private clinics and government hospitals as well as private hospitals. Across the groups, women (both literate and illiterate) were found to be more inclined toward doctors, whereas husbands favored doctors and hospitals the least. About two- 
thirds of the women have shown their highest confidence in doctors, seeing them as the ultimate health care providers in case of complications.

A lady doctor is educated, well trained and can handle all complications that may arise during delivery. (Illiterate woman, Khanewal)

We trust a lady doctor only because they can forecast whether the delivery case would be normal or would require an operation. She can use ultrasound machine to tell us about the position of the baby and also gives the right medicines. (Literate woman, Khanewal)

$A$ doctor is well equipped for his/her work, whereas with a TBA one never knows and the situation becomes life threatening. I'm just scared of a TBA. (Illiterate woman, Jhelum)

The doctors at private hospitals take good money therefore they have to take care of the patients as well. (Literate woman, Jhelum)

It is only the doctors who can give quality health care services, they usually give right advice. (Literate woman, Dadu)

Interestingly, across the districts, TBAs tended to favor doctors more than LHVs. Probably the TBAs saw the a doctor as the natural step ahead from them who could provide better reproductive health care services so the TBAs were more open to this admittance. On the other hand, the LHVs seemed to consider themselves to be quite capable and were less likely to acknowledge the superiority of the doctors very easily. Regarding satisfactory reproductive health services, the most vocal of all the groups were the women. This may be because it is the women who come in direct contact with the health care providers.

Lady doctor is better because she is literate and can do ultra sound. (TBA, Jhelum)

It is noteworthy that the participants who admitted that only doctors in private clinics and hospitals could provide the most satisfactory reproductive services also voiced several concerns about the quality of the services provided by the doctors. These concerns include lack of availability of all health care services, such as injections, medicine, operation theatre and ancillary facilities, at one place, plus the high fees and the indifferent attitude of doctors in the hospitals.

Lady doctors say bring this medicine and bring that medicine, they know it's a matter of life and death and they exploit that. They ask us to arrange money and we often have to get a loan. They charge us Rs. 1,000 for an injection that costs a fraction of that. We are illiterate so we do not know. We have to do it to save the life of the woman. (Illiterate woman, D.G. Khan) 
I went to the hospital with my daughter-in-law, she was in very bad condition, only junior doctors examined her, a senior lady doctor was there but she did not bother to even look at my daughter-inlaw and she just suffered lying in the hospital unattended. (Mother-in-law, Dadu)

Across the districts, a few participants, mostly husbands and illiterate women, expressed absolute dissatisfaction with the quality of services provided by the doctors, particularly in the government hospitals. It was reported that in government hospitals one was only looked after properly if one had contacts at the right places (e.g., with hospital employees). Moreover, the doctors in such hospitals constantly tried to steer the patient toward their private clinics where they charged a higher fee.

Often when we take women to the government hospital in Dadu they tell us to take the patient to a bigger hospital in Hyderabad or Larkana because hospitals in smaller cities do not bave all the facilities. (Husband, Dadu)

Across the groups, some participants from Dadu and D.G. Khan and a couple of participants from Jhelum, mentioned the LHV as a satisfactory health care provider for women during pregnancy and delivery. Among these participants, younger literate women supported LHVs more strongly than the other groups. The reasons for satisfaction with the services of LHVs pertained mostly to them being more skilled, attentive, caring, more easily accessible, and economical. On the other hand, across the districts, a few participants, mostly husbands and mothers-in-law, expressed their dissatisfaction with LHVs as health care providers. In Khanewal, a significant number of the participants, primarily LHVs and TBAs, mentioned an LHV as a satisfactory health care provider for women during pregnancy and delivery. Their reasons for satisfaction with LHV services pertained mostly to LHVs being more skilled, attentive, caring, more easily accessible, a guide and a teacher for TBAs, having a strong referral network, and economical. Positive and negative statements include:

LHVs can bandle complications related to child delivery; for instance, in case of extra bleeding she can give an injection. (Literate woman, Dadu)

I go to an LHV because she is very nice and gives time and listens to me with full attention. (Illiterate woman, D.G. Khan)

The LHV s are not skilled enough to handle deliveries properly. (Husband, Jhelum)

LHVs are young girls who know notbing, have no experience, and cannot handle a difficult delivery case. (Mother-in-law, D.G. Khan)

An LHV has more experience and skill, they can manage complicated cases so when TBAs cannot handle a case they bring them to $L H V$, and she also guides and teaches TBAs new and useful information. (TBA, Khanewal)

$L H V$ s complete a professional course and they are skilled, if blood is required then the LHV can 
arrange for that, when a baby is born assisted by an LHV then we are at peace that she will handle any situation. (Husband, Khanewal)

Across the groups, some participants from D.G. Khan, Khanewal and a few from Jhelum and Dadu stated that a TBA could provide satisfactory health care services albeit only for normal delivery cases. The reasons for considering TBAs to be satisfactory health care provider is primarily related to greater accessibility, timely availability, lower costs and extensive experience in handling normal delivery cases. A perception that cut across the groups and districts was that the TBAs could handle normal deliveries only; even those who considered the services of TBAs to be satisfactory shared this perception. TBAs were more popular in the D.G. Khan than the other three districts. A significant number of literate women from D.G. Khan expressed their confidence in the adequacy of services provided by the TBAs. A probable reason for the relatively higher acceptance of TBAs in D.G. Khan could be that in that district it was reported to be a common practice for older women of extended families to perform the duties of a TBA for the younger women of their family.

The main advantage of getting treatment from a TBA is that it saves money. (Mother-in-law, D.G. Khan)

$T \mathrm{~TB}$ is always available at the time of delivery and costs very little compared to the government or private hospitals. (Husband, Khanewal)

A TBA is more attentive towards the patient and we don't have to travel far to reach her. (Literate woman, D.G. Khan)

TBAs are experienced; she comes to check on a woman daily sometimes even twice. It's also a matter of affordability. (Husband, D.G Khan)

It is noteworthy that many women (literate and illiterate) and husbands, primarily from Dadu, Khanewal and Jhelum, expressed strong dissatisfaction with the services provided by the TBA. The highest level of dissatisfaction was expressed in Dadu and Khanewal, and the lowest in D.G. Khan.

The TBA has no proper knowledge; she solely relies on her experience. Sometimes her experience sees her through, sometimes it does not! (Literate woman, Dadu)

$T B A$ is illiterate she does not know anything, she can neither do proper delivery nor can she provide adequate post-delivery care. (Illiterate woman, Khanewal)

A TBA cannot use injections or administer a drip, she takes a chance if the baby delivers normally then its fine, but if a complication occurs she simply tells the family to take the woman in labor to a hospital, which is dangerous for the woman in question. (Literate woman, Khanewal)

To summarize, among all of the health care providers, only doctors were non-controversial, although many issues related to doctors' attitudes and costs were highlighted. Following on from the doctors, LHVs were more acceptable and less controversial than TBAs. 


\subsection{Advantages of Using LHVs}

LHVs and TBAs are the primary competitors of CMWs; therefore, perceptions regarding the services of these two health care providers were thoroughly investigated by asking direct questions. The opinion regarding advantages of an LHV-assisted delivery varied across the districts and groups. More than half of the participants, predominantly mothers-in-law, literate women and some illiterate women, primarily from Dadu, and D.G. Khan, reported various advantages of an LHV-assisted delivery. However, very few participants from Jhelum and about one-fourth of the participants from Khanewal reported any such advantages. The most stated advantage was that an LHV could provide a wider range of services, including family planning services, provision of medicine and other health care services (e.g., injections, drips, blood pressure checkups, ultrasound, etc.). Other advantages mentioned were the LHVs strong theoretical (academic) knowledge about reproductive health issues, technical skills to handle complications, higher accessibility (compared with doctors/hospitals), cost effectiveness, hygiene consciousness, and a more sympathetic attitude than the doctors. Among all the groups the, literate women most emphasized the LHVs strong educational background and formal training and ability to provide family planning services.

\section{LHVs give us complete information regarding treatment; they can administer glucose drip, injections and give medicines. They are present in our locality so we don't have to go into town and they provide all facilities. (Mother-in-law, Dadu)}

The good thing about LHVs is that right after a delivery that she conducts, she starts advising her clients on correct family planning methods. (Literate woman, D.G. Khan)

An LHV has all the facilities except Caesarian section, and she can bandle most of the complications very well, she can administer IV drip that helps quicken the labor pains, she provides the right kind of care for newborns as well. (Literate woman, Khanewal)

It is noteworthy that a considerable number of TBAs admitted that LHVs have superior skills and knowledge and are better equipped to handle difficult deliveries with the help of medicines and injections than TBAs.

We call our LHV 'baji' [elder sister] and take complicated cases to her, she is literate and ganges through 'shisha' [ultra sound machine] at early stages if the child is weak (not growing adequately). (TBA, D.G. Khan) 
An LHV is very well trained and can tell the position of the baby correctly well in advance and if Caesarean section is required she refers to the hospital and this allows people time to make arrangements for hospital delivery. (TBA, Khanewal)

Across the districts, the fee reported for LHVs was less than that of doctors and more than that of TBAs. Across the districts, flexible fee structures were reported: rich clients/patients were charged more than the poor clients/patients were. Also higher fees were charged for complicated cases where an episiotomy was performed. Across the districts, fees charged by LHVs for a delivery ranged from Rs. 500 to 6,000; the most commonly reported fees ranged from Rs. 1,000 to 2,000. An interesting dimension of the fee structure, reported across the districts and groups, was that a higher fee was charged when a boy was born than when the newborn was a girl.

There is no fixed fee. When I deliver at people's own homes, I see the financial condition of the family and charge accordingly -- for normal delivery I often charge Rs. 1,000 to 1,500. (LHV from Dadu)

If a girl is born then people give up to 500 or so and if it is a boy they give additional 'mubariki' [celebratory/congratulatory] money and we easily make around Rs. 1,000. We pray more than the parents that the child born should be a boy, because when a girl is born people are so angry at us, as if it is our fault that it is a girl. (LHV from Jhelum)

A few TBAs, mothers-in-law, husbands and illiterate women from Dadu and Jhelum stated that there was no advantage in an LHV-assisted delivery and many of them expressed a clear preference for a doctor-assisted delivery. A probable reason could be that husbands were less aware about the presence and role of both LHWs and LHVs, and many failed to make a distinction between the two. Across the districts, more husbands expressed their ideas about the advantages of TBAs and/or doctor-assisted deliveries.

A doctor is better, LHVs cannot do stitches properly as they are not trained for that, it is a matter of life and death, so better go to a doctor who knows what she is doing. (Literate woman, Jhelum)

Across the groups, a little less than half of the participants, primarily from D.G. Khan and Dadu, and less than one-sixth of the participants, primarily LHVs, and illiterate women from Khanewal, stated multiple advantages of TBA assisted deliveries. The primary advantages of TBAs mentioned across the districts and groups were cost effectiveness and availability of service at home. Among the groups, women (illiterate and literate), particularly from D.G. Khan, emphasized the low cost factor much more than other groups. The availability of services of TBAs to women within their homes was much more strongly emphasized by LHVs across the districts.

The biggest advantage is that the Rs. 4,000 to 5,000 spent at the LHV's can be saved, instead only Rs. 400 to 500 bundred is spent. TBAs look after us and protect us within our bomes. (Literate woman, D.G. Khan) 
People prefer a TBA because she comes to the home and is always available even at night. (LHV, D.G. Khan)

Other reported advantages of TBAs were the depth of their experience, easy accessibility, their belonging to the community, trusted by the family members, provision of a wide range of services of a highly exclusive nature, such as body massage for the mother, washing of baby's dirty napkins, bathing the baby, and cooking special/traditional food for the mother. Finally, the ability of TBAs to recognize the correct time to refer to the doctor during pregnancy and delivery was seen as a major advantage by many.

After the delivery, she gives the mother a body massage daily, cooks special food for the mother, washes the dirty clothes of the mother and child and looks after them for 15 days following the delivery. (Mother-inlaw, Dadu)

She does a complete checkup, if she feels she cannot handle the delivery, she refers the woman to a doctor. (Mother-in-law, Dadu)

A significant number of women, husbands, mothers-in-law and LHVs across the districts stated that there was no particular advantage of a TBA-assisted delivery and doctors were the better option.

As compared to other health care providers, the fees charged by TBAs were the lowest and the most flexible. Checkups during pregnancy were offered free of charge by the TBAs, whereas the charges for child delivery ranged anywhere from Rs. 100 to 2,000. The most commonly reported amounts were less than Rs. 1,000. A unique feature reported across the districts and groups about the fee structure of TBAs was flexibility. Multiple dimensions of the flexible fee structure were reported, as there existed a vastly different price range for the rich and the poor. Reportedly, TBAs charged different fees from people of different classes, asking more of financially comfortable people and less of the poor. Also, payment could be made in kind as well with items, such as sugar, wheat, ghee, clothes, a baby goat, and sweetmeats. TBAs also offered services in return of a promise of deferred payment.

When someone cannot afford the fee, TBAs are happy with a box of sweets or clothes; they don't ask for money and are satisfied by the Rs. 200 to 300 given to them. (Husband, D.G Khan)

There is no fixed fees a dai charges, she takes whatever you give ber and is open to negotiations. (Mother-inlaw, Dadu)

TBAs charge Rs. 200 to 1,000 depending on what a family can afford; she does not have a fixed fee and knows the inside story of the financial conditions of each family in the village, so she does not argue about her fee. (Literate woman, Khanewal)

One advantage of dais is that they charge very little and if we don't have money we give them a baby goat. (Illiterate woman, D.G. Khan) 
Another interesting dimension of the fees charged by TBAs, reported across the districts by a much larger number of participants from Dadu and D.G. Khan, was that TBAs asked for different payments depending on the sex of the newborn. In case of the birth of a boy, reportedly the TBA's fee not only increased by a good 25-50 percent, but the TBA also demanded additional 'mubariki' money (celebratory/congratulatory money). It was customary to give bonus goods (as mentioned above) and congratulatory clothes (jora).

If a boy is born, they take clothes, sugar and ghee, and if it's a girl they take up to Rs. 200. (Husband, Jhelum)

When a boy is born the TBA says make me bappy because you've been blessed with a son. (Literate women, D.G. Khan)

Across the districts and groups, a few participants saw no advantages in TBA-assisted deliveries.

$T B A$ just use herbal and home remedies and look after the ne born baby because they are experienced in such matters; a TBA can't handle a complicated case so she is useless as she doesn't know anything. There are no literate TBAs here, all of them are illiterate. Yes, a TBA does a checkup if there is no other option, but otherwise she doesn't understand much. (Husband, Jhelum)

To summarize: the advantages of both LHV- and TBA-assisted deliveries are related mainly to skills and costs. Slowly but surely the trend is shifting toward formally trained health care providers. In a way, parallels are being drawn between the experience and traditional knowledge of TBAs with the LHVs use of medical equipment and medicines. Both LHVs and TBAs demanded considerably more as delivery fee when a boy was born. This is probably because of the deep-rooted social biases that sons are considered as potential financial assets and daughters as financial burdens. Thus, the birth of a boy is an event of great exuberance where the TBA and LHV are paid for their services much more generously. 


\subsection{Acceptability of CMWs}

A major objective of the present study was to assess the potential acceptability of CMWs. The research sites selected were the catchment areas of CMWs; however, in most places, CMWs selected from those areas were still under training when research data were collected. Therefore, in order to determine the acceptability, the following standard description of CMWs was shared with the participants. Based on this description, the FGD participants were asked questions related to potential acceptability of the CMWs.

The Government of Pakistan is introducing a trained woman in your community, who will provide health faculties to pregnant woman and newborn babies, and will also deliver babies. This woman will be from your own community. She will come back after her training and serve pregnant woman in your community. Do you have any idea about a woman who had this training in your community?

There was a consensus across the districts and groups that there was a need in their communities for a trained health care professional, such as a CMW.

We don't have a doctor in our village, she will educate us about health and would belp us with deliveries, and our area will flourish. (Illiterate woman, D.G. Khan)

After our delivery there is nobody to go to and women often fall sick because of that. There is a need for $C M W$. (Literate woman, Dadu)

We will benefit a lot from a CMW's presence in the community; she will guide us about child care and about bealth issues pre- and post- delivery. (Literate woman, Khanewal)

Across the districts and groups (except LHVs), the majority agreed that CMWs would be easily and unanimously acceptable to the communities. A majority of the participants agreed that the attitude of most community members would be positive and respectful toward CMWs.

CMWs would belp us and we will belp them, we will deal with her good-naturedly because she will be preserving our future generations. (Husband, Jhelum)

We will be nice to the CMW because she will be belping us in our time of need. (Illiterate woman, Jhelum)

CMWs will provide services to women, and people will definitely have a positive attitude toward CMWs.

(Husband, Khanewal)

Some TBAs, LHVs and mothers-in-law from Dadu pointed toward potential resistance. These participants mentioned that to gain acceptability a CMW should be able to maintain good relations with all the influential landlords in her catchment area. A TBA from Dadu captured the general sentiment very well (below). A few MILs and husbands from Dadu expressed a fear that TBAs might 
oppose CMWs primarily because the presence of CMWs would decrease the demand for TBAs services.

There was a TBA in a village near ours and the 'vadera' of that village would not let her go to the villages under the control of his opponent 'vadera' even if a woman in labor would suffer for hours or die. (Motherin-law, Dadu)

People will not oppose her; they will be highly thankful for the facility. The 'vaderay' [influential land owners with large land holdings] would also support her if she gives them enough importance and starts her work with their blessing and keeps the women of their families happy with her services and attitude. (TBA, Dadu)

A significant number of participants, mostly professional competitors of CMWs - LHVs and TBAs said that acceptance of a CMW would primarily depend on her performance.

If she is good in her work, we will refer her to other people, the same as we had done with Naseembar, an LHV who delivered my baby. (Literate woman, Jhelum)

People will respect and accept CMW only if she provides adequate services to women, and has a cooperative attitude toward people. (Husband, Khanewal)

Other critical factors identified regarding potential acceptability of CMWs were almost similar across the districts and groups. These factors included conformity to local norms and friendly and respectful behavior toward her clients.

Overall, the research findings indicated that CMWs as health care providers might not face strong resistance from any quarter; however, building a reasonable level of clientele might be a slow and long process. A significant number of LHVs and a few TBAs highlighted the likely challenges that a CMW could face in establishing a medical practice in her community. These challenges related to developing effective working relations with TBAs and LHVS, building reliable referral networks, establishing fee structures compatible with TBAs and LHVs, fulfilling the very high expectations that community members have from all formally trained health care providers, regardless of the kind of medical degree they might have.

\section{Although the CMW will have training, she won't have experience and people will not accept her unless she has experience. (LHV, Dadu)}

Across the districts, LHVs maintained that CMW were likely to be bracketed with LHVs, and, according to LHVs, people were far more accepting of mistakes made by TBAs as compared to LHVs. Similarly, even doctors could get away with deaths because they were usually away from people's reach, but a CMW in this regard would be closer to an LHV, and, in a similar manner, would be subjected to severe scrutiny of performance. 
A TBA can announce to the family in an early stage of a delivery that if this woman lives on, she's yours, if she dies, she's Allah's -- and people still accept and trust her, an LHV or CMW would never be able to do that. (LHV, Jhelum)

Both the LHVs and the TBAs, mostly from D.G. Khan, highlighted that TBAs had deep connections with the families often spanning generations; hence, switching over to another health care provider, such as a CMW, would not be easy for those families.

Even if young women want to go to $C M W$ s, their mothers-in-law won't allow it because each family has a family TBA to whom all the women of the family go and she is totally trusted by other family members, particularly husbands. (LHV, D.G. Khan)

In summary, CMWs are most likely to be given a level playing field; how well they establish themselves would primarily depend on their performance. Multiple dimensions of the expected performance are discussed in detail in the following section.

\subsection{Expectations about CMWs}

A wide range of expectations about the CMWs was expressed that broadly related to five areas in the following order of preference:

1. Availability/accessibility

2. Knowledge/skills

3. Attitudes/behavior

4. Availability of facilities

5. Fee structures

Among these, the most often stated quality was accessibility of a CMW around the clock and getting timely assistance in case of an emergency. Though this expectation was reported across the districts, participants from Jhelum emphasized this aspect a little more. Across the groups, women (literate and illiterate) placed more emphasis on easy accessibility of a CMW. Various aspects of accessibility were discussed, including around the clock service at home, frequent trips to houses of expectant mothers, accessibility by mobile phone in case of emergency, and the availability of a car so that a CMW could reach the patient on time.

She should be available at all times and should reach us as soon as we call her. She should have a mobile phone with a good sim so there is no problem of reception. (Literate woman, Jhelum)

She should have access to a car at all times, so she can reach us when we call her. (Illiterate woman, Dadu) 
CMW's door should be open for us at all times. (Literate woman, D.G. Khan)

A CMW should be available 24 hours for women in labor, at her clinic and also, if the condition of woman demands, she should provide her services at the doorstep, only then she can be useful for the community and we will be saved the trouble of taking women to far away hospitals. (Husband, Khanewal)

Participants across all of the districts and groups verbalized expectations related to skills and knowledge of CMWs. However, mothers-in-law and literate women from Dadu and Jhelum emphasized this aspect more than others did. Regarding skills and knowledge, the most emphasized facets were that a CMW should be well educated, able to handle complicated cases, prescribe the correct medicines, administer IV drips and injections, perform ultrasound, check blood pressure and blood glucose levels and, most importantly, be able to do an episiotomy ${ }^{7}$ (chotta operation). Emphasized almost equally across the districts, the third major expectation about the CMW was that she should have a friendly and cooperative attitude. Across the groups, this expectation was stated only by mothers-in-law, women (literate and illiterate) and husbands. It is interesting that attituderelated expectations were not mentioned by TBAs and LHVs at all. This expectation, which was verbalized in one brief sentence, "Us ka raviya accha bo" (she should have a good attitude), proved to be an all-encompassing phrase. Various dimensions of this expectation were highlighted, such as: CMW should treat rich and poor equally but should charge less from the poor. She should work in collaboration with the local dais and LHVs, respect not only her patients but also their families, treat women within their homes, should be humble, have a sympathetic attitude, and, finally, should be able to satisfy her patients.

$C M W$ should be available to women around the clock in her bome-based clinic, she should not snub women who go to her and should listen to ber patients attentively. (Literate woman, Khanewal)

Women should be able to tell her their problems easily, and she should be able to guide them. (Illiterate woman, D.G. Khan)

$C M W$ should not have an attitude like doctors, she should listen to us and be friendly with women. (Husband, Dadu)

The range of facilities that CMWs were expected to offer was very similar to what a medical doctor would provide, including ultrasound facility, blood pressure measurement, blood glucose level

7 An episiotomy is a surgical incision through the perineum made to enlarge the vagina and assist childbirth. The incision can be midline or at an angle from the posterior end of the vulva, is performed under local anesthetic and is sutured closed after delivery. It is one of the most common medical procedures performed on women 
checkup, injections, drips and all kinds of medicines.

We run to the hospitals in the cities because they have all the machines and through these doctors can judge the situation of a mother in labor; it is easier for us to go to a CMW if she has similar facilities. (Husband, Khanewal)

$C M W$ should do proper checkup with alla (ultrasound) and should charge Rs. 50 for this. (Illiterate woman, D.G. Khan)

Expectations related to fee structures were explored separately for CMWs and as compared to the fees of LHVs and TBAs; the findings are discussed in the section below.

\subsection{Fee Structure}

Fee structures of health care providers are often a critical factor in determining the accessibility of health care services; therefore, acceptable levels of fees for CMWs were explored in depth. Expectations, regarding the amount of fee the CMWs should be charging, were expressed at two levels: the fee for checkups (both pre- and post-delivery) and the fee for deliveries.

Across all districts, less than one-fifth of the participants, primarily TBAs, MILs, illiterate women and husbands, suggested that CMWs should not charge a fee for routine checkups during pregnancy and the post-natal period. Multiple reasons were given to justify this proposition; i) most people in the rural communities were poor could not afford a fee ii) government should pay CMW like other health care providers such as LHV and LHW and staff in government hospitals where routine checkups fees were not charged and iii) TBAs did not charge a fee for pre- and post-natal checkups.

The CMW should be on the pay roll of the government and thus take nothing from the community people." (Mother-in-law, Jhelum)

The purpose of actually belping out the poor would only be met if the CMWs do not burden them with checkup fees. (Literate woman, Dadu)

Across the groups, women, especially literate ones were more willing to pay the CMW a fee for checkups during pregnancy. A little less than half of the participants who were willing to pay for checkups considered amounts ranging from Rs. 20 to 50 appropriate, which is very much in line with the reported fee paid to an LHV for a pre-natal checkup.

For the village people Rs. 20 are fine for monthly checkup as the poor cannot bear more than that, some can pay up to Rs. 50 but those are few. (Literate woman, Jhelum)

Across the districts and groups, a majority of participants were willing to pay a CMW for assisting in delivery. The range of the fee recommended varied greatly- from Rs. 100 to 1,000. In Khanewal, the most acceptable fee for delivery ranged from Rs. 300-500, two-thirds of the husbands, some women 
and mothers-in-law suggested this amount. A significant number of literate women and LHVs considered Rs. 500-1,000 as a reasonable amount for delivery. These participants argued that since the expenditure for taking a woman to the city eventually could add up to a far bigger sum, this amount was reasonable for having a safe delivery at home. Across the districts, women (mostly literate) and husbands had suggested a higher fee for the delivery. LHVS and TBAs from across the districts recommended the lowest fee structure for CMWs.

Across the other three districts, about one-third of the participants, mostly husbands and literate women, suggested Rs. 400 to 500 as a reasonable amount for the delivery fee. Across the districts, a little less than one-third of the participants, half of them LHVs and TBAs, suggested CMWs should charge up to Rs. 200 for a delivery. Another argument put forward, mostly by LHVs and TBAs in favor of this amount, was that only through a lower and flexible fee structure would a CMW be able to attract people to use her services.

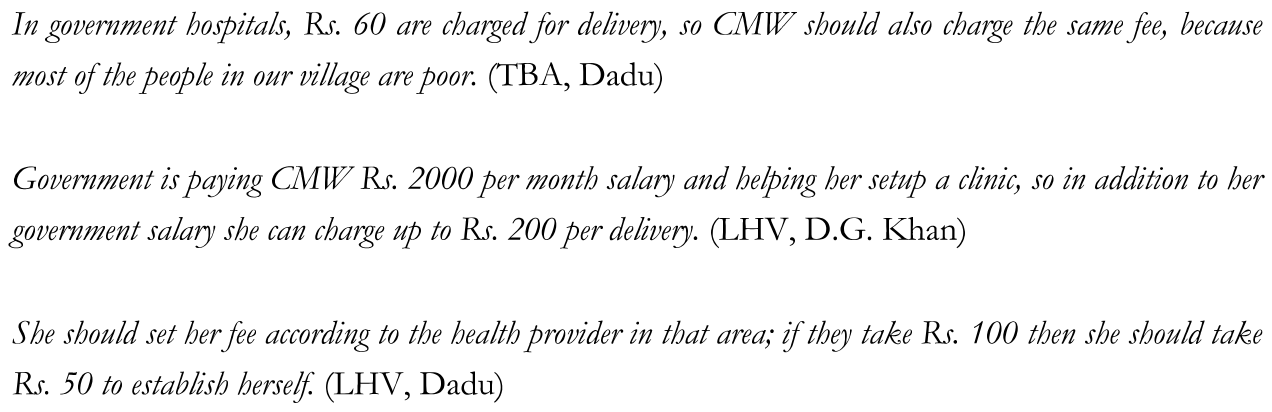

A significant number of participants, mostly women and husbands from Jhelum and Dadu, were of the view that they could pay from Rs. 900 to 1,000. It is interesting that a few participants, women, husbands and MILs, were willing to pay even more than Rs. 1,000. These participants argued that since the expenditure for taking a woman to the city eventually could add up to a far bigger sum, paying this amount instead was reasonable for having a safe delivery at home. A husband from Dadu commented:

If we go toward the city, the expenditure for us can total to as big an amount as Rs. 10 to 15 thousand; at
bome it will be done safely and husbands will have peace of mind. (Husband, Dadu)

A few participants, mostly MILs, suggested that the government should set a delivery fee for the CMW instead of allowing communities and CMWs to decide themselves. Across the districts, particularly from Dadu, less than one-fifth of the participants, mostly MILs, LHVs and a few husbands, recommended that the CMW should not charge at all for conducting deliveries, instead they should be paid by the government.

Government is sending CMW for the help of poor, so they should not charge for delivery from them, if they give a box of sweetmeats out of their own choice she should accept it. (Mother-in-law, D.G. Khan) 
The most important aspect of the fee issue was that, in line with the current practices of LHVs and TBAs, the participants, in general, expected a "sliding scale fee structure" that would make exceptions for the poor, asking less money from them than from the rich.

A CMW should charge us according to our situation, if a person is unemployed she should charge less, and if someone is earning well she should charge them a higher fee. (Illiterate woman, Dadu)

In this community, families have lots of dependent children and very little cash income; therefore, people cannot pay high fees for delivery. CMWs should expect that some families would be able to pay Rs. 500 to 1,000 and others Rs. 100 to 200, and some may not be able to pay at all. She should accommodate all of them like we do. (LHV, Khanewal)

In summary, the fee structure of the CMWs will be compared with the fees of existing health care providers (doctors, LHVs and TBAs) and will be judged accordingly

\subsection{Perspective of TBAs and LHVs.}

LHVs and TBAs perceived CMWs as a potential competitor, and agreed that the presence of CMWs would adversely affect their level of clientele. However, at the same time, LHVs and TBAs also recognized their two distinct advantages: more experience and existing connection with the families.

Across the districts a majority of the TBAs and LHVs were of the opinion that CMWs would be better skilled and more knowledgeable than the TBAs.

$C M W$ will be better because the government has trained ber, she would know how to turn on oxygen machines, take blood pressure and do ultrasound. (A TBA from Dadu)

Across the districts, and particularly from D.G. Khan, TBAs stated that the CMW would not be able to take over all of her domain. TBAs provide services that include massaging a woman for a few days before and after delivery, washing baby's and mother's clothes, cooking special food for the mother, making traditional herbal concoctions, daily home visits for checkups before and after delivery, and accompanying a pregnant woman to a hospital in case of complications. In Khanewal, all of the TBAs readily admitted that CMWs would affect their clientele very badly. A majority of TBAs were willing to take all complicated delivery cases to CMWs and assist them in delivery.

People cannot leave us because we offer services like massage, washing, etc., which a $C M W$ cannot do. (TBA, D.G. Khan)

We can work together, that will be beneficial for both of us, CMW will be in the community and the cases I cannot manage, I will take them to her. (TBA, Khanewal) 
The opinions of the LHVs regarding the professional ranking of a CMW in relation to an LHV varied across districts, and the nature of recommended collaboration varied accordingly. The LHVs from the districts of Dadu and D.G. Khan considered CMWs in their own league, almost at par with them professionally; they admitted that CMWs could replace LHVs in the end. According to most LHVs from Jhelum, a CMW belonged to a lower level of health professionals than that of an LHV. This argument was supported by the fact that the training of LHVs was of longer duration (one additional year of course work in public health). In Khanewal, the opinion of LHVs was divided on this issue; a little less than half of the LHVs said their work/clientele would not be affected, while the remaining LHVs strongly felt that their clientele would be adversely affected. Many LHVs emphasized that they were more skilled and experienced than the CMWs and, hence, had a distinct advantage over CMWs.

It is like the rings of a ladder, CMW is to refer complicated delivery cases to LHV and we refer to one step abead [i.e., doctors in District Headquarters Hospital]. (LHV, Jhelum)

A significant number of LHVs recognized that CMWs have advantages over LHVs -- being from the same community and staying in the same community. Several LHVs across the districts admitted that CMWs could replace LHVs eventually. Both TBAs and LHVs expressed their willingness to work with the CMWs and pointed to distinct mechanisms for collaboration. The TBAs identified the following areas of collaboration:

\section{Referring all delivery cases to CMW}

2. Calling on CMW for difficult/complicated deliveries

3. Assisting CMW during delivery and providing other services (massage, cleaning, washing) for the delivery cases conducted by a CMW

In return, TBAs expected a 50 percent share of the CMWs fee in delivery cases when they assisted by providing supplementary services during and after delivery and about 30-40 percent if they refer cases to a CMW. It is noteworthy that TBAs, particularly the ones from D.G. Khan and Khanewal, were very confident that they could play an important role in promoting CMWs in their communities.

Women in the community would know about the presence and skills of a CMW when we tell them; when we recommend them only then the families will accept CMWs. (TBA, Khanewal)

LHVs, in line with their perceptions, proposed a different mechanism of cooperation with the CMWs. LHVs from D.G. Khan and Dadu suggested a division of territory - LHVs work till 2 p.m. or in defined clinic timings, and in the areas closer to their residence or clinic. A CMW could conduct deliveries post-LHV clinic timings because a CMW would be managing a home-based clinic. LHVs from Jhelum and Khanewal recommended two ways of collaboration: first, a CMW could refer all 
delivery cases to an LHV and take an agreed percentage of the delivery fees that the LHV would charge; second, a CMW could carry out the normal delivery cases herself and in case of complications could refer the case to an LHV. LHVs from Jhelum were willing to give the CMW 25 percent share in the fee on all normal cases that the CMW would refer to an LHV.

$C M W s$ should refer difficult cases to us; if she behaves like an LHV then it will not work, the same as an LHV cannot substitute for Woman Medical Officer. (LHV from Jhelum)

$C M W s$ have been trained and they might think, too much of themselves and would like to bandle cases on their own so that they could charge a fee, rather than referring the cases to LHVs. (LHV, Khanewal)

n summary, the collaboration mechanisms suggested primarily based on sharing in the fee charged for delivery. Depending on the nature of collaboration, the range of sharing varied from 25 to 50 percent of the fee. 


\section{Recommendations}

\section{Sensitize family members}

Mothers-in-law and husbands should be sensitized and motivated so that they are more willing to grant permission to the pregnant woman to consult a CMW. The government could run media campaigns to raise awareness of problems during pregnancy and delivery. Concerted efforts would be required to inform husbands about the presence of CMWs in the community, as the level of awareness among husband about the presence and specific roles of health care providers in the community seemed to be low. The government could involve local government representatives, either the Union Council Nazim or its Councilors, and social activists to introduce the CMWs.

\section{Develop flexible and compatible fee structures}

In line with the existing community based health care providers; TBAs and LHVs, a sliding scale fee structure is expected from the CMWs as well. The flexibility in the fee structures offered by the TBAs was highly appreciated by the communities and was considered a major reason of seeking services of the TBAs. CMWs may not be able to practice that level of flexibility and it is not advisable either; however, CMWs may have to include some flexibility in their fee structures, e.g., deferred payments and different rates for well-off and poor clients.

\section{Give clients greater accessibility}

The most desired expectation is the ability to have instant and 24-hour access to CMWs, particularly around the time of delivery. Home visits, flexible clinic hours and availability via cell phone are some of the ways that could enhance accessibility.

\section{Build a network of resources}

CMWs, with the assistance of the district health department, should develop formal linkages with local NGOs, charity organizations (e.g., Edhi Foundation) and corporate sector organizations (national and multinational industrial entities) to facilitate provision of a vehicle to take women to a hospital in emergency cases. In return, these organizations may be provided with opportunities for advertisement. The CMW may also collaborate with local taxi owners to provide these services at pre-determined rates.

\section{Establish collaborative mechanisms with local TBAs}

The initial phase of gaining acceptance in the community, when CMWs would be perceived by dais and LHVs as competitors, could be transformed into a phase of coexistence with TBAs, where the CMWs would have established their position as skilled birth attendants (SBAs) who are technically superior to the dais. TBAs could continue with delivering uncomplicated cases, while referring difficult cases to CMWs, for this purpose a sharing in the fee charged for delivery would be expected by the TBAs. 


\section{Annex}

\section{Annex 1: Profile of Researchers}

\begin{tabular}{|c|c|c|c|c|}
\hline No. & Name & Education & Language spoken & $\begin{array}{r}\text { Experience in } \\
\text { research }\end{array}$ \\
\hline 01 & Ahmed Hassan & $\begin{array}{l}\text { M. Sc (Defense \& Strategic } \\
\text { Studies) }\end{array}$ & $\begin{array}{l}\text { Pothwari / English / } \\
\text { Urdu / Punjabi }\end{array}$ & 3 Years \\
\hline 02 & Ghulam Mustafa & M. Phil & English / Punjabi / Urdu & 2 Years \\
\hline 03 & Muhammad Bilal Asmat & M. Sc (Anthro) & $\begin{array}{l}\text { Sarike / English / Urdu / } \\
\text { Punjabi }\end{array}$ & 1 Year \\
\hline 04 & Nazia Dayo & M.A (Sociology) & English / Urdu / Sindhi & 2 Years \\
\hline 05 & Rehana Khan & M.A (Sociology) & $\begin{array}{l}\text { English / Urdu / Sindhi / } \\
\text { Punjabi }\end{array}$ & 3 Years \\
\hline 06 & Saira Memon & M.A (Economic) & $\begin{array}{l}\text { English / Urdu / Sindhi / } \\
\text { Sarike }\end{array}$ & 12 years \\
\hline 07 & Saira Chaudry & $\begin{array}{l}\text { M.A (Sociology) } \\
\text { M.A (Economic) }\end{array}$ & $\begin{array}{l}\text { Urdu / English / Sindhi / } \\
\text { Sarike }\end{array}$ & 8 Years \\
\hline 08 & Azra Jabeen & B.A (humainities) & $\begin{array}{l}\text { Urdu / Hindko / Punjabi } \\
\text { / Pahari }\end{array}$ & 8 Years \\
\hline 09 & Sidra Mushtaq & $\begin{array}{l}\text { Masters in International } \\
\text { Relation \& LHV }\end{array}$ & Urdu / Punjabi / Sarike & 2 Months \\
\hline 10 & Aneela Yasmeen & B. Com & Urdu / Sarike & 5 Years \\
\hline 11 & Shazia Malik & B.A & Urdu / Sarike & 4 Years \\
\hline 12 & Maryam Iqbal & M. Sc (Anthropology) & Urdu / Punjabi & 1 Year \\
\hline 13 & Saira Murie & M. Sc (Anthropology) & $\begin{array}{l}\text { Urdu / English / Pushto } \\
\text { / Punjabi }\end{array}$ & 6 Months \\
\hline 14 & Tooba Rafi & M. Sc (Anthropology) & Urdu / English & 4 Months \\
\hline 15 & Lutaf Ali Mangrio & M. Sc (Anthropology) & $\begin{array}{l}\text { Urdu / English / Sindhi / } \\
\text { Punjabi }\end{array}$ & 4 Years \\
\hline 16 & Inayat Ali Shah & M.A (Sociology) & Urdu / English / Sindhi & 3 Years \\
\hline 17 & Noor-ul-Ain Ali & M. Sc (Anthropology) & Urdu / Punjabi / English & 1 Year \\
\hline 18 & Maria Qibria & M. Sc (Anthropology) & Urdu / Punjabi / English & 4 Months \\
\hline 19 & Shehzadi Nosheen & M.A English & $\begin{array}{l}\text { Sarike, Punjabi, Urdu, } \\
\text { English, }\end{array}$ & 11 year \\
\hline 20 & Abdul Qadir & M.A & $\begin{array}{l}\text { Sarike, punjabi, Urdu, } \\
\text { English, }\end{array}$ & 5 years \\
\hline 21 & Aftab Mungi & M.A (Economics) & Sindhi, "Urdu, English & 5 years \\
\hline
\end{tabular}




\section{Annex 2: FGD Guidelines}

\section{A.2.1 FGD Guidelines for Husbands}

\section{Topic 1. Opinion, importance, benefits and drawbacks of present health} providers / facilities in the community and who is better and how

1. Who are the people and institutions for the treatment of woman during the pregnancy and for delivery? How far are they?

$>$ Midwifes, LHV, lady doctor, BHU, RHC, THQ, DHQ, hospital, social welfare and others.

$>$ Who are the ones who visit home? And who do you have to visit and where?

2. Who do you think can be a satisfactory medical/health provider to a pregnant woman?

$>$ Midwife, LHV, LHW etc.

$>$ And why?

$>$ Why are other health providers not considered good?

$>$ What are the benefits of delivery conducted by a midwife?

$>$ What are the benefits of delivery conducted by a LHV?

\section{Topic 2. Problems in access to health provider/facilitator}

1. Do think, a woman, during pregnancy or for delivery, should go to a health provider/facilitator for treatment?

$>$ Where and why? What is their fee?

2. What are the difficulties in accessing health provider/facilitator during pregnancy or for delivery?

$>$ Distance, expenditure, transport, family customs, and attitude of health provider etc.

3. Should a woman ask someone for permission for her treatment during the pregnancy and for delivery?

$>$ If yes, then from whom and why?

$>$ Does a woman have to take permission from both the mother in law and the husband?

$>$ If there is no need to ask for permission then why?

$>$ Do the women take permission in your community?

$>$ Whether they get the permission easily or not?

$>$ Ask both (about delivery and during pregnancy)?

4. What do think, do people feel embarrassed in taking women to hospitals for delivery?

5. In case of emergency how do you arrange for transportation?

6. What do you think, can common people easily bear the cost of transportation and other related costs incurred to access health facilities? 


\section{Topic 3. Expectation of community from CMW \\ Introduction of CMW}

The Government of Pakistan is introducing a trained woman in your community, who will provide health faculties to pregnant woman and newborn babies, and will also deliver babies. This woman will be from your own community. She will come back after her training and serve pregnant woman in your community. Do you have any idea about a woman who had this training in your community?

1. What kind of medical facilities should a CMW provide to pregnant women?

2. What skills should a CMW have?

$>$ What specific skills should she have, what should she be an expert in?

3. How should she behave with the people in your community?

4. What should be her fee?

$>$ Why this much?

$>$ How much can a poor, ordinary family afford?

5. What should be the family background of a CMW?

6. Is there any possibility, that a link among CMW, LHV and midwife can be built?

$>$ If yes, then what kind of?

$>$ If not, then why?

\section{Topic 4. Attitude of competitors and community towards CMWs}

1. What will be your attitude towards the CMWs?

$>$ Will you accept them? If yes, then why? And if no, then why not?

2. What do you think will be the behavior/attitude of people/community towards the CMWs?

$>$ Will they accept them? If yes, then why? If no, then why not?

3. Who will not accept them?

$>$ Midwife, LHV, LHW, etc.

4. How will you convince those who will oppose CMWs?

5. What difference will come to mother's and child's health with the arrival of CMW?

\section{A.2.2 FGD Guidelines for Women}

Topic 1. Danger signs during pregnancy and after delivery, why do you think they are dangerous and to what extent

1. What do you think are the complications can a woman face during pregnancy? And how can they affect on the health of a child?

2. What kind of the complications can a woman face during and after the pregnancy? And how can they affect on mother's health?

3. What are the complications can a newborn child face immediately after birth? And how can they affect child's health? 
Topic 2. Opinion, importance, benefits and drawbacks of present health providers/ facilities in the community and who is better and how

1. Who are the people and which institutions are considered for the treatment of women during pregnancy and for delivery? How far are they?

Whether a woman has to take permission from both the mother in law and the husband?

> Midwifes, LHV, lady doctor, BHU, RHC, THQ, DHQ, hospital, social welfare and others.

$>$ Who are the ones who visit houses? And who do you have to visit and where?

2. Who do you think can be a satisfactory medical/health provider to a pregnant woman?

$>$ Midwife, LHV, LHW etc.

$>$ And why?

$>$ Why are other health providers not considered good?

$>$ What are the benefits of a delivery done by midwife?

$>$ What are the benefits of a delivery done by LHV?

\section{Topic 3. Problems in accessing health provider/facilitator}

1. What do you think, should a woman during pregnancy or for delivery go to a health provider/facilitator for treatment?

$>$ Where and why? What is their fee?

2. 2 What are difficulties in accessing health provider/facilitator during pregnancy or for delivery?

$>$ Distance, expenditure, transport, family customs, and attitude of health provider etc.

3. Should a woman ask someone for permission for her treatment during pregnancy and for delivery?

$>$ If yes, then from whom and why?

$>$ Whether a woman has to take permission from both, the mothers in law and the husband?

$>$ If there is no need to ask for permission then why?

$>$ Do the women take permission in your community?

$>$ Whether they get the permission easily or not?

$>$ Ask both (about delivery and during pregnancy)?

4. What do think, what is the preferable place for delivery?

$>$ Why?

$>$ If hospital then why not home?

$>$ If home then why not hospital?

5. Which is the place preferred by most women for delivery in your community?

$>$ Why? 


\section{Topic 4. Expectations of community from CMW}

\section{Introduction of CMW}

The Government of Pakistan is introducing a trained woman in your community, who will provide health faculties to pregnant women and newborn babies, and will also deliver babies. This woman will be from your own community. She will come back after her training and serve pregnant women your community. Do you have any idea about a woman who has had this training in your community?

1. What kind of medical facilities should a CMW provide to pregnant women?

2. What skills should a CMW have?

$>$ What should be her specific skills, what should she be expert in?

3. How should she behave with the people in your community?

4. What should be her fee?

$>$ Why this much?

$>$ How much can a poor, ordinary family afford?

5. What should be the family background of a CMW?

6. Is there any possibility, that a link among the CMW, LHV and midwife can be built?

$>$ If yes, then what kind of?

$>$ If not, then why not?

\section{Topic 5. Attitude of competitors and community towards CMW}

1. What will be your attitude towards the CMWs?

$>$ Will you accept them? If yes then why? And if no then why not?

1. What do you think will be the behavior/attitude of people/community towards CMWs?

$>$ Will they accept them? If yes, then why? If no then, why not?

2. Who will not accept them?

$>$ Midwife, LHV, LHW etc.

3. How will you convince those who oppose the introduction of CMWs?

4. What difference will come to mother's and child's health with the arrival of CMW? 


\section{A.2.3 FGD Guidelines for LHVs and TBAs}

Topic 1. Danger signs during pregnancy and after delivery, to what extent do you think they are dangerous

1. What do you think are the complications a woman can face during pregnancy? How can they affect the health of the child?

2. What kind of complications can a woman face during and after delivery? How can they affect the mother's health?

3. What complications can a newborn child face immediately after birth? How can they affect the child's health?

Topic 2. Different medical workers/providers of present health care facilities in the community

1. Who are the people present in your community who provide the treatment for pregnant women and the delivery?

$>$ Midwifes, LHV, LHW, etc.

$>$ Who is better and how?

2. Who are the people preferred by most women for their treatment during pregnancy?

$>$ Are they satisfied with their work?

3. Is there a need for more skillful medical workers in the community?

$>$ Do you think the number of referrals will decrease with the presence of these workers?

4. What are the expectations of people from these health providers?

Topic 3. Problems in accessing health providers

1. What are the difficulties a woman has to face in accessing the health providers during pregnancy and for delivery?

$>$ Expenditure, Transport, Family, Customs, Permission, Behavior of the health providers.

5. Do women in your community have to take permission to go to a health provider during pregnancy and for delivery?

$>\quad$ If yes, then from whom? Do they get permission easily?

6. Who is the decision maker (at home) for the treatment a woman is to get during pregnancy and for delivery in the community? (From whom one should be treated, when and why?)

7. Do you have the facility of transport in case of an emergency? 


\section{Topic 4. Health workers' attitudes toward CMW}

\section{Introduction of CMW}

The government of Pakistan is introducing a trained woman in your community who is to provide health facilities to pregnant women and newborn babies, and will deliver the babies. This woman will be from within the community; she will come back after her training and serve pregnant women in your community. Do you have any idea about such a woman in your community?

1. What do you think about the idea of introducing CMWs by the government?

$>$ If it is good, then tell us how and why?

$>$ If not, then why?

2. Do you think your work will be affected with the arrival of CMWs?

$>$ If yes then how?

$>$ If no, then why not?

3. Can you work together with the CMWs?

$>$ If yes then how?

$>$ If no, then why not?

4. Do you think CMWs will be helpful to you in some way?

$>$ If yes then how?

$>$ If no, then why not?

5. Do you think CMWs will be more skillful than you? 


\section{Topic 5. Attitude of community toward CMW}

1. What do you think will be the attitude of the community towards the CMWs? Will they accept them or oppose them?

2. Who will oppose them?

3. Do you think you can play some role in convincing the opposing people?

$>$ If yes, then how?

4. Do you think they will get preference over midwives? Why?

5. Do you think they will get preference over LHVs? Why?

6. What should be her fees?

$>$ Why this much?

$>$ How much can the poor afford to pay? 


\section{Annex 3: Demographic Tables}

Table A.3.1: Number of FGD participants by age, group and district

\begin{tabular}{|c|c|c|c|c|c|c|c|c|c|c|c|c|}
\hline \multirow[b]{2}{*}{ District } & \multirow[b]{2}{*}{ Group } & \multicolumn{10}{|c|}{ Age group } & \multirow[b]{2}{*}{ Tota } \\
\hline & & $15-20$ & 21-25 & $26-30$ & $31-35$ & $36-40$ & 41-45 & $46-50$ & $51-55$ & $56-60$ & 61-65 & \\
\hline \multirow[t]{6}{*}{ Dadu } & Husbands & 1 & 3 & 4 & 2 & 4 & 2 & 3 & 0 & 1 & 0 & 20 \\
\hline & Literate women & 0 & 6 & 3 & 2 & 0 & 2 & 1 & 0 & 0 & 0 & 14 \\
\hline & Illiterate women & 0 & 3 & 5 & 3 & 4 & 1 & 0 & 0 & 0 & 0 & 16 \\
\hline & Mothers-in-law & 0 & 0 & 0 & 0 & 1 & 1 & 3 & 5 & 7 & 0 & 17 \\
\hline & LHVs & 0 & 4 & 1 & 4 & 3 & 0 & 0 & 1 & 0 & 0 & 13 \\
\hline & TBAs & 0 & 0 & 2 & 0 & 0 & 0 & 3 & 4 & 6 & 0 & 15 \\
\hline \multirow[t]{6}{*}{ D. G. Khan } & Husbands & 0 & 1 & 5 & 6 & 3 & 0 & 0 & 0 & 0 & 0 & 15 \\
\hline & Literate women & 3 & 9 & 3 & 3 & 0 & 0 & 0 & 0 & 0 & 0 & 18 \\
\hline & Illiterate women & 6 & 9 & 1 & 3 & 1 & 0 & 0 & 0 & 0 & 0 & 20 \\
\hline & Mothers-in-law & 0 & 0 & 0 & 0 & 1 & 3 & 5 & 3 & 5 & 0 & 17 \\
\hline & LHVs & 1 & 3 & 5 & 3 & 1 & 0 & 0 & 0 & 0 & 0 & 13 \\
\hline & TBAs & 0 & 0 & 1 & 1 & 1 & 1 & 4 & 2 & 3 & 0 & 13 \\
\hline \multirow[t]{6}{*}{ Jhelum } & Husbands & 0 & 0 & 3 & 4 & 1 & 1 & 3 & 0 & 2 & 0 & 14 \\
\hline & Literate women & 6 & 5 & 5 & 2 & 0 & 0 & 0 & 0 & 0 & 0 & 18 \\
\hline & Illiterate women & 1 & 4 & 2 & 1 & 4 & 1 & 0 & 0 & 0 & 0 & 13 \\
\hline & Mothers-in-law & 0 & 0 & 0 & 0 & 2 & 0 & 7 & 2 & 4 & 0 & 15 \\
\hline & LHVs & 0 & 2 & 8 & 2 & 0 & 0 & 0 & 0 & 1 & 0 & 13 \\
\hline & TBAs & 0 & 0 & 0 & 2 & 2 & 2 & 4 & 0 & 0 & 3 & 13 \\
\hline \multirow[t]{6}{*}{ Khanewal } & Husbands & & 3 & 7 & 0 & 2 & 1 & 0 & 0 & 0 & 0 & 13 \\
\hline & Literate women & 3 & 5 & 5 & 2 & 1 & 0 & 0 & 0 & 0 & 0 & 16 \\
\hline & Illiterate women & 0 & 7 & 8 & 2 & 1 & 0 & 0 & 0 & 0 & 0 & 18 \\
\hline & Mothers-in-law & 0 & 0 & 0 & 0 & 1 & 5 & 6 & 3 & 5 & 0 & 20 \\
\hline & LHVs & 0 & 1 & 0 & 5 & 4 & 0 & 0 & 3 & 0 & 0 & 13 \\
\hline & TBAs & 1 & 3 & 4 & 2 & 1 & 4 & 1 & 2 & 0 & 0 & 18 \\
\hline \multicolumn{2}{|l|}{ Total } & 22 & 68 & 72 & 49 & 38 & 24 & 40 & 25 & 34 & 3 & 375 \\
\hline
\end{tabular}


Table A.3.2: Number of FGD participants by years of education, group and district

\begin{tabular}{|c|c|c|c|c|c|c|c|c|c|c|c|c|c|c|}
\hline \multirow[b]{2}{*}{ District } & \multirow[b]{2}{*}{ Group } & \multicolumn{12}{|c|}{ Years of education } & \multirow[b]{2}{*}{ Total } \\
\hline & & 0 & 1 & 2 & 3 & 4 & 5 & 6 & 7 & 8 & 9 & 10 & $>10$ & \\
\hline \multirow[t]{5}{*}{ Dadu } & Husbands & 5 & 0 & 0 & 1 & 0 & 5 & 0 & 0 & 4 & 0 & 4 & 1 & 20 \\
\hline & Women & 11 & 0 & 3 & 1 & 1 & 4 & 6 & 0 & 0 & 0 & 4 & 0 & 30 \\
\hline & Mother-in-law & 16 & 0 & 0 & 0 & 0 & 1 & 0 & 0 & 0 & 0 & 0 & 0 & 17 \\
\hline & TBAs & 13 & 1 & 0 & 1 & 0 & 0 & 0 & 0 & 0 & 0 & 0 & 0 & 15 \\
\hline & LHVs & 0 & 0 & 0 & 0 & 0 & 0 & 0 & 0 & 0 & 0 & 1 & 12 & 13 \\
\hline \multirow[t]{5}{*}{ DG Khan } & Husbands & 7 & 0 & 0 & 0 & 0 & 1 & 1 & 1 & 4 & 1 & 0 & 0 & 15 \\
\hline & Women & 18 & 0 & 0 & 1 & 0 & 0 & 6 & 2 & 5 & 0 & 6 & 0 & 38 \\
\hline & Mothers-in-law & 7 & 0 & 0 & 0 & 0 & 4 & 0 & 0 & 1 & 0 & 3 & 2 & 17 \\
\hline & TBAs & 12 & 0 & 0 & 0 & 0 & 0 & 0 & 0 & 0 & 0 & 1 & 0 & 13 \\
\hline & LHVs & 0 & 0 & 0 & 0 & 0 & 0 & 0 & 0 & 0 & 0 & 2 & 11 & 13 \\
\hline \multirow[t]{5}{*}{ Jhelum } & Husbands & 1 & 0 & 0 & 0 & 0 & 1 & 1 & 0 & 2 & 4 & 5 & 0 & 14 \\
\hline & Women & 8 & 0 & 2 & 3 & 0 & 3 & 0 & 0 & 3 & 0 & 11 & 1 & 31 \\
\hline & Mothers-in-law & 13 & 0 & 0 & 1 & 1 & 0 & 0 & 0 & 0 & 0 & 0 & 0 & 15 \\
\hline & TBAs & 8 & 0 & 0 & 0 & 0 & 3 & 0 & 0 & 2 & 0 & 0 & 0 & 13 \\
\hline & LHVs & 0 & 0 & 0 & 0 & 0 & 0 & 0 & 0 & 0 & 0 & 4 & 9 & 13 \\
\hline \multirow[t]{5}{*}{ Khanewal } & Husbands & 6 & 0 & 0 & 0 & 2 & 0 & 0 & 1 & 2 & 2 & 0 & 0 & 13 \\
\hline & Women & 18 & 0 & 0 & 0 & 0 & 0 & 8 & 1 & 6 & 0 & 1 & 0 & 34 \\
\hline & Mothers-in-law & 16 & 0 & 0 & 0 & 0 & 1 & 0 & 0 & 1 & 1 & 1 & 0 & 20 \\
\hline & TBAs & 11 & 0 & 0 & 0 & 1 & 2 & 0 & 0 & 3 & 0 & 1 & 0 & 18 \\
\hline & LHVs & 0 & 0 & 0 & 0 & 0 & 0 & 0 & 0 & 0 & 0 & 4 & 9 & 13 \\
\hline \multicolumn{2}{|l|}{ Total } & 170 & 1 & 5 & 8 & 5 & 25 & 22 & 5 & 33 & 8 & 48 & 45 & 375 \\
\hline
\end{tabular}


Table A.3.3: Number of FGD participants by number of children, group and district

\begin{tabular}{|c|c|c|c|c|c|c|c|c|c|c|c|c|c|c|c|c|c|}
\hline \multirow[b]{2}{*}{ District } & \multirow[b]{2}{*}{ Group } & \multicolumn{16}{|c|}{ Number of children } \\
\hline & & 0 & 1 & 2 & 3 & 4 & 5 & 6 & 7 & 8 & 9 & 10 & 11 & 12 & 13 & 14 & Total \\
\hline \multirow[t]{4}{*}{ Dadu } & Husbands & 0 & 2 & 2 & 6 & 2 & 3 & 1 & 2 & 0 & 1 & 0 & 0 & 1 & 0 & 0 & 20 \\
\hline & Literate women & 0 & 2 & 4 & 2 & 1 & 3 & 0 & 1 & 0 & 1 & 0 & 0 & 0 & 0 & 0 & 14 \\
\hline & Illiterate women & 0 & 1 & 2 & 4 & 1 & 3 & 1 & 1 & 0 & 0 & 1 & 0 & 0 & 2 & 0 & 16 \\
\hline & Mothers-in-law & 0 & 2 & 6 & 4 & 0 & 0 & 0 & 0 & 3 & 0 & 0 & 0 & 0 & 2 & 0 & 17 \\
\hline \multirow[t]{4}{*}{ DG Khan } & Husbands & 0 & 0 & 4 & 2 & 3 & 1 & 2 & 0 & 1 & 2 & 0 & 0 & 0 & 0 & 0 & 15 \\
\hline & Literate women & 0 & 6 & 3 & 3 & 0 & 1 & 1 & 4 & 0 & 0 & 0 & 0 & 0 & 0 & 0 & 18 \\
\hline & Illiterate women & 0 & 6 & 3 & 3 & 2 & 1 & 1 & 1 & 1 & 1 & 0 & 0 & 1 & 0 & 0 & 20 \\
\hline & Mothers-in-law & 0 & 3 & 0 & 0 & 0 & 4 & 0 & 0 & 0 & 1 & 1 & 0 & 1 & 7 & 0 & 17 \\
\hline \multirow[t]{4}{*}{ Jhelum } & Husbands & 0 & 4 & 1 & 4 & 1 & 0 & 1 & 0 & 1 & 1 & 0 & 1 & 0 & 0 & 0 & 14 \\
\hline & Literate women & 0 & 7 & 9 & 2 & 0 & 0 & 0 & 0 & 0 & 0 & 0 & 0 & 0 & 0 & 0 & 18 \\
\hline & Illiterate women & 0 & 1 & 4 & 2 & 3 & 2 & 1 & 0 & 0 & 0 & 0 & 0 & 0 & 0 & 0 & 13 \\
\hline & Mothers-in-law & 0 & 3 & 4 & 1 & 2 & 1 & 2 & 2 & 0 & 0 & 0 & 0 & 0 & 0 & 0 & 15 \\
\hline \multirow[t]{5}{*}{ Khanewal } & Husbands & 0 & 3 & 2 & 2 & 1 & 0 & 0 & 3 & 2 & 0 & 0 & 0 & 0 & 0 & 0 & 13 \\
\hline & Literate women & 0 & 5 & 2 & 2 & 2 & 3 & 1 & 1 & 0 & 0 & 0 & 0 & 0 & 0 & 0 & 16 \\
\hline & Literate women & 1 & 2 & 4 & 2 & 4 & 2 & 1 & 2 & 0 & 0 & 0 & 0 & 0 & 0 & 0 & 18 \\
\hline & Mothers-in-law & 3 & 4 & 4 & 5 & 0 & 0 & 0 & 0 & 2 & 1 & 1 & 0 & 0 & 0 & 0 & 20 \\
\hline & Total & 4 & 51 & 54 & 44 & 22 & 24 & 12 & 17 & 10 & 8 & 3 & 1 & 3 & 11 & 0 & 264 \\
\hline
\end{tabular}

Table A.3.4: Number of FGD participants by age of youngest child/grandchild, group and district

\begin{tabular}{|c|c|c|c|c|c|c|c|c|}
\hline District & Group & 0 & $<1$ year & $1-2$ & $2-3$ & $3-4$ & $4-5$ & Total \\
\hline \multirow[t]{3}{*}{ Dadu } & Husbands & 0 & 2 & 5 & 4 & 8 & 1 & 20 \\
\hline & Women & 0 & 10 & 5 & 5 & 10 & 0 & 30 \\
\hline & Mothers-in-law & 0 & 8 & 5 & 1 & 1 & 2 & 17 \\
\hline \multirow[t]{3}{*}{ DG Khan } & Husbands & 0 & 6 & 4 & 1 & 4 & 0 & 15 \\
\hline & Women & 0 & 12 & 11 & 3 & 4 & 8 & 38 \\
\hline & Mothers-in-law & 0 & 2 & 2 & 2 & 4 & 7 & 17 \\
\hline \multirow[t]{3}{*}{ Jhelum } & Husbands & 0 & 1 & 4 & 6 & 3 & 0 & 14 \\
\hline & Women & 0 & 10 & 8 & 4 & 5 & 4 & 31 \\
\hline & Mothers-in-law & 0 & 9 & 1 & 3 & 1 & 1 & 15 \\
\hline \multirow[t]{3}{*}{ Khanewal } & Husbands & 0 & 7 & 6 & 0 & 0 & 0 & 13 \\
\hline & Women & 3 & 6 & 16 & 9 & 0 & 0 & 34 \\
\hline & Mothers-in-law & 0 & 6 & 8 & 5 & 1 & 0 & 20 \\
\hline \multicolumn{2}{|l|}{ Total } & 3 & 79 & 75 & 43 & 41 & 23 & 264 \\
\hline
\end{tabular}


Table A.3.5: Number of FGD husbands by occupation, group and district

\begin{tabular}{|c|c|c|c|c|c|c|c|c|c|c|c|c|c|c|c|c|c|}
\hline \multirow[b]{2}{*}{ Occupation } & \multicolumn{4}{|c|}{ Jhelum } & \multicolumn{4}{|c|}{ DG Khan } & \multicolumn{4}{|c|}{ Dadu } & \multicolumn{4}{|c|}{ Khanewal } & \multirow[b]{2}{*}{ Total } \\
\hline & $\begin{array}{l}\frac{0}{0} \\
\frac{c}{\pi} \\
\frac{0}{0} \\
\stackrel{0}{2} \\
\text { I }\end{array}$ & 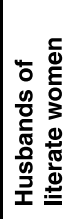 & 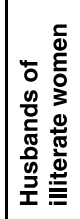 & 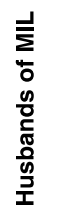 & 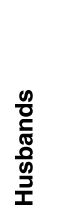 & 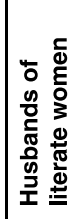 & 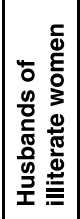 & 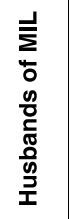 & 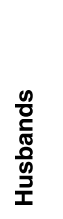 & 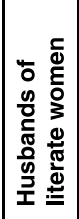 & 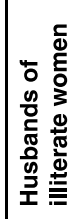 & 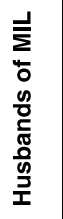 & $\begin{array}{l}\frac{0}{8} \\
\frac{0}{50} \\
\frac{0}{0} \\
\frac{0}{9} \\
\frac{1}{1}\end{array}$ & 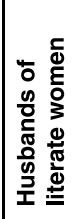 & 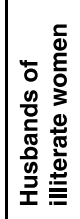 & 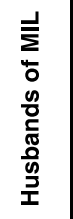 & \\
\hline Laborer & 1 & 5 & 3 & 1 & 7 & 2 & 10 & 0 & 4 & 2 & 0 & 2 & 4 & 12 & 13 & 13 & 79 \\
\hline Govt. servant & 2 & 6 & 1 & 1 & 2 & 5 & 0 & 4 & 3 & 5 & 7 & 2 & 2 & 1 & 0 & 1 & 42 \\
\hline Shopkeeper & 2 & 2 & 1 & 0 & 0 & 0 & 0 & 1 & 2 & 0 & 2 & 1 & 4 & 0 & 0 & 1 & 16 \\
\hline Farmer & 8 & 1 & 3 & 7 & 5 & 5 & 4 & 4 & 9 & 1 & 3 & 7 & 2 & 0 & 0 & 0 & 59 \\
\hline $\begin{array}{l}\text { Private } \\
\text { business }\end{array}$ & 0 & 0 & 1 & 0 & 1 & 0 & 1 & 1 & 1 & 0 & 0 & 0 & 0 & 0 & 0 & 0 & 5 \\
\hline Dry cleaner & 0 & 0 & 0 & 0 & 0 & 0 & 0 & 0 & 1 & 0 & 0 & 1 & 0 & 0 & 0 & 0 & 2 \\
\hline $\begin{array}{l}\text { Retired govt. } \\
\text { servant }\end{array}$ & 1 & 0 & 0 & 6 & 0 & 0 & 0 & 0 & 0 & 0 & 0 & 2 & 0 & 0 & 0 & 0 & 9 \\
\hline Driver & 0 & 4 & 3 & 0 & 0 & 3 & 0 & 1 & 0 & 3 & 2 & 0 & 0 & 0 & 0 & 0 & 16 \\
\hline $\begin{array}{l}\text { Private } \\
\text { servant }\end{array}$ & 0 & 0 & 0 & 0 & 0 & 2 & 0 & 0 & 0 & 1 & 2 & 0 & 0 & 0 & 0 & 0 & 5 \\
\hline Foreign & 0 & 0 & 0 & 0 & 0 & 1 & 5 & 0 & 0 & 0 & 0 & 0 & 0 & 0 & 0 & 0 & 6 \\
\hline $\begin{array}{l}\text { Homeopathic } \\
\text { doctor }\end{array}$ & 0 & 0 & 0 & 0 & 0 & 0 & 0 & 0 & 0 & 0 & 0 & 0 & 0 & 1 & 0 & 1 & 2 \\
\hline $\begin{array}{l}\text { Cook in } \\
\text { roadside } \\
\text { hotel }\end{array}$ & 0 & 0 & 0 & 0 & 0 & 0 & 0 & 0 & 0 & 0 & 0 & 0 & 0 & 0 & 2 & 1 & 3 \\
\hline Army officer & 0 & 0 & 0 & 0 & 0 & 0 & 0 & 0 & 0 & 0 & 0 & 0 & 0 & 1 & 0 & 0 & 1 \\
\hline Tailor & 0 & 0 & 0 & 0 & 0 & 0 & 0 & 0 & 0 & 0 & 0 & 0 & 0 & 0 & 1 & 0 & 1 \\
\hline Mason & 0 & 0 & 0 & 0 & 0 & 0 & 0 & 0 & 0 & 0 & 0 & 0 & 0 & 0 & 0 & 1 & 1 \\
\hline Conductor & 0 & 0 & 0 & 0 & 0 & 0 & 0 & 0 & 0 & 0 & 0 & 0 & 0 & 0 & 1 & 0 & 1 \\
\hline $\begin{array}{l}\text { No } \\
\text { information }\end{array}$ & 0 & 0 & 0 & 0 & 0 & 0 & 0 & 2 & 0 & 0 & 0 & 2 & 0 & 0 & 0 & 2 & 6 \\
\hline Unemployed & 0 & 0 & 1 & 0 & 0 & 0 & 0 & 4 & 0 & 2 & 0 & 0 & 0 & 0 & 0 & 0 & 7 \\
\hline Total & 14 & 18 & 13 & 15 & 15 & 18 & 20 & 17 & 20 & 14 & 16 & 17 & 12 & 15 & 17 & 20 & 261 \\
\hline
\end{tabular}

$M I L=$ mothers-in-law 
Table A.3.6: Number of TBAs and LHVs by number of children delivered in last 2 months and district

\begin{tabular}{|c|c|c|c|c|c|c|c|c|c|c|c|c|c|}
\hline \multirow[b]{2}{*}{ District } & \multirow[b]{2}{*}{ Group } & \multicolumn{12}{|c|}{ Number of children } \\
\hline & & $<5$ & $5-10$ & $11-15$ & $16-20$ & $21-25$ & $26-30$ & $31-35$ & $36-40$ & $41-45$ & $46-50$ & $51-55$ & Total \\
\hline \multirow[t]{2}{*}{ Dadu } & TBAs & 7 & 3 & 3 & 2 & 0 & 0 & 0 & 0 & 0 & 0 & 0 & 15 \\
\hline & LHVs & 5 & 1 & 6 & 1 & 0 & 0 & 0 & 0 & 0 & 0 & 0 & 13 \\
\hline \multirow[t]{2}{*}{ DG Khan } & TBAs & 6 & 2 & 3 & 2 & 0 & 0 & 0 & 0 & 0 & 0 & 0 & 13 \\
\hline & LHVs & 2 & 3 & 4 & 2 & 0 & 0 & 0 & 0 & 0 & 2 & 0 & 13 \\
\hline \multirow[t]{2}{*}{ Jhelum } & TBAs & 5 & 5 & 3 & 0 & 0 & 0 & 0 & 0 & 0 & 0 & 0 & 13 \\
\hline & LHVs & 1 & 1 & 4 & 2 & 2 & 0 & 1 & 1 & 1 & 0 & 0 & 13 \\
\hline \multirow[t]{2}{*}{ Khanewal } & TBAs & 16 & 2 & 0 & 0 & 0 & 0 & 0 & 0 & 0 & 0 & 0 & 18 \\
\hline & LHVs & 7 & 4 & 1 & 1 & 0 & 0 & 0 & 0 & 0 & 0 & 0 & 13 \\
\hline Total & & 49 & 21 & 24 & 10 & 2 & 0 & 1 & 1 & 1 & 2 & 0 & 111 \\
\hline
\end{tabular}

Table A.3.7: Number of TBAs and LHVs by years of experience and district

\begin{tabular}{|c|c|c|c|c|c|c|c|c|c|c|c|c|c|c|c|}
\hline \multirow[b]{2}{*}{ District } & \multirow[b]{2}{*}{ Group } & \multicolumn{13}{|c|}{ Years of experience } & \multirow[b]{2}{*}{ Total } \\
\hline & & $1-2$ & $3-4$ & $5-6$ & $7-8$ & $9-10$ & 11-12 & 13-14 & $15-16$ & $17-18$ & $19-20$ & 21-22 & 23-24 & $>25$ & \\
\hline \multirow[t]{2}{*}{ Dadu } & TBAs & 0 & 3 & 1 & 1 & 0 & 1 & 0 & 2 & 2 & 0 & 2 & 0 & 3 & 15 \\
\hline & LHVs & 3 & 3 & 0 & 1 & 0 & 3 & 1 & 0 & 2 & 0 & 0 & 0 & 0 & 13 \\
\hline \multirow[t]{2}{*}{ DG Khan } & TBAs & 0 & 0 & 0 & 0 & 0 & 2 & 0 & 6 & 0 & 1 & 1 & 0 & 3 & 13 \\
\hline & LHVs & 4 & 0 & 1 & 0 & 4 & 2 & 0 & 2 & 0 & 0 & 0 & 0 & 0 & 13 \\
\hline \multirow[t]{2}{*}{ Jhelum } & TBAs & 1 & 2 & 1 & 3 & 0 & 1 & 4 & 0 & 0 & 1 & 0 & 0 & 0 & 13 \\
\hline & LHVs & 2 & 0 & 2 & 5 & 0 & 0 & 0 & 2 & 2 & 0 & 0 & 0 & 0 & 13 \\
\hline \multirow[t]{2}{*}{ Khanewal } & TBAs & 0 & 7 & 3 & 0 & 2 & 0 & 0 & 4 & 2 & 0 & 0 & 0 & 0 & 18 \\
\hline & LHVs & 0 & 0 & 0 & 1 & 0 & 1 & 3 & 3 & 1 & 1 & 3 & 0 & 0 & 13 \\
\hline \multicolumn{2}{|l|}{ Total } & 10 & 15 & 8 & 11 & 6 & 10 & 8 & 19 & 9 & 3 & 6 & 0 & 6 & 111 \\
\hline
\end{tabular}




\section{라를 \\ JSI Research \& Training Institute, Inc.}

CA\#391 A-00-05-01037 is funded by the United States Agency for International Development and implemented by JSI Research \& Training Institute, Inc.

In conjunction with Aga Khan University, Contech International, Johns Hopkins University / CCP, The Population Council, Save the Children USA 